GLOBAL SYNTHETIC DRUGS ASSESSMENT 2020 


\section{Global Synthetic Drugs Assessment 2020}

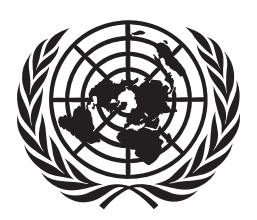

UNITED NATIONS

Vienna, 2020 
(C) United Nations, November 2020. All rights reserved worldwide.

United Nations publication, Sales No. E.20.XI.9

ISBN: $\quad 978-92-1-148353-6$

eISBN: 978-92-1-005483-6

This publication may be reproduced in whole or in part and in any form for educational or non-profit purposes without special permission from the copyright holder, provided acknowledgement of the source is made. The United Nations Office on Drugs and Crime (UNODC) would appreciate receiving a copy of any publication that uses this publication as a source.

Suggested citation:

Global Synthetic Drugs Assessment 2020 (United Nations publication, Sales No. E.20.XI.9).

No use of this publication may be made for resale or any other commercial purpose whatsoever without prior permission in writing from UNODC. Applications for such permission, with a statement of purpose and intent of the reproduction, should be addressed to the Research and Trend Analysis Branch of UNODC.

\section{Disclaimer}

The content of this publication does not necessarily reflect the views or policies of UNODC or contributory organizations, nor does it imply any endorsement. This document has not been formally edited.

Comments on the report are welcome and can be sent to:

Laboratory and Scientific Section

Division for Policy Analysis and Public Affairs

United Nations Office on Drugs and Crime

P.O. Box 500

1400 Vienna

Austria

Tel.: (+43) 1260600

Email: unodc-globalsmart@un.org

Website: www.unodc.org/lab

This publication has not been formally edited.

Publishing production: English, Publishing and Library Section, United Nations Office at Vienna. 


\section{Acknowledgments}

The Global Synthetic Drugs Assessment 2020 was prepared by the UNODC Laboratory and Scientific Section under the supervision of Angela Me, Chief of the Research and Trend Analysis Branch (RAB), and Justice Tettey, Chief of the Laboratory and Scientific Section (LSS).

\section{Supervision and review}

Justice Tettey

Martin Raithelhuber

\section{Analysis and drafting}

Conor Crean

Sabrina Levissianos

Tun Nay Soe

Inshik Sim

Joey Yang Yi Tan

\section{Editing}

Clare Jones de Rocco

Data management and mapping support

Tsegahiwot Abebe Belachew

Nael Elagabani

Katharina Maria Rodler
The Laboratory and Scientific Section would like to thank the following Governments who made the development of this report possible through their contributions to the Global SMART Programme:

\author{
Government of Australia \\ Government of Canada \\ Government of China \\ Government of Japan \\ Government of New Zealand \\ Government of the Republic of Korea \\ Government of the Russian Federation \\ Government of Singapore \\ Government of Thailand \\ Government of the United Kingdom \\ Government of the United States
}

The present report also benefited from the expertise and valuable contributions of UNODC colleagues in the Regional Office for South-East Asia and the Pacific including Alexandru Caciuloiu and Himal Ojha.

The report also benefited from the work and expertise of many other UNODC staff members in Vienna and around the world. 



\section{Contents}

Acknowledgments . . . . . . . . . . . . . . . . . . .

Explanatory notes $\ldots \ldots \ldots \ldots \ldots \ldots \ldots \ldots \ldots \ldots \ldots \ldots \ldots \ldots \ldots \ldots \ldots$ vii

General abbreviations ............................. viii

Chemical abbreviations. . . . . . . . . . . . . .

GLOBAL OVERVIEW $\quad$ X

Options for response $\ldots \ldots \ldots \ldots \ldots \ldots \ldots \ldots \ldots \ldots \ldots \ldots \ldots \ldots \ldots \ldots$

Impact of the COVID-19 pandemic on the sale of synthetic drugs . . . . . . . . . 4

Trends in trafficking and use of synthetic drugs. . . . . . . . . . . . . . . . 6

Methamphetamine: a dynamic and growing market . . . . . . . . . . . 6

Amphetamine: the growing impact of "captagon" ................ 7

An expanding market for "ecstasy" . . . . . . . . . . . . . . . . . 8

New psychoactive substances: expansion of synthetic opioids

and benzodiazepine-type new psychoactive substances ............. 10

The non-medical use of opioids is expanding: fentanyl and tramadol. . . . . . . . 11

Trends in the manufacture of synthetic drugs . . . . . . . . . . . . . . . . . 12

Regional diversity in amphetamine and methamphetamine precursor developments............................... 14

Precursor chemicals in the manufacture of "ecstasy" . . . . . . . . . . 15

Precursor trends in the illicit manufacture of fentanyl and its analogues . . . . 16

REGIONAL OVERVIEW 17

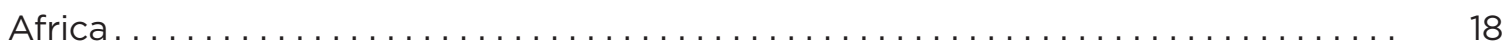

Americas...................................... 20

Central America, South America and the Caribbean . . . . . . . . . . . . . 21

North America. . . . . . . . . . . . . . . . . . . . . . . . . . . . 23

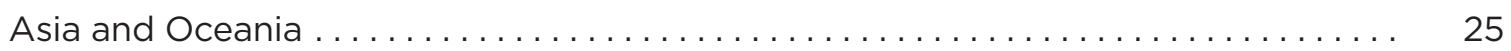

Central Asia and Transcaucasia. . . . . . . . . . . . . . 26

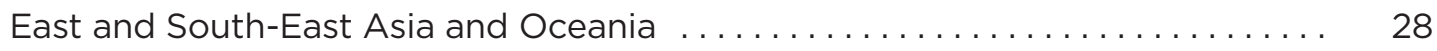

The Near and Middle East .......................... 30

South Asia $\ldots \ldots \ldots \ldots \ldots \ldots \ldots \ldots \ldots \ldots \ldots \ldots \ldots \ldots \ldots \ldots \ldots \ldots \ldots \ldots \ldots$

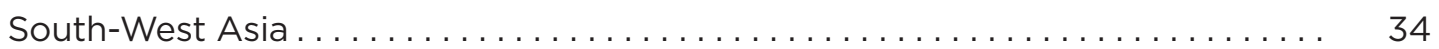

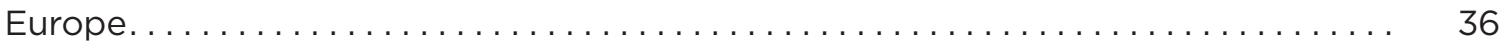

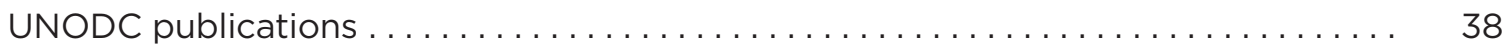

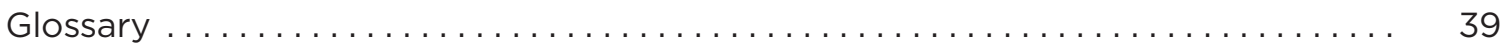

Regional groupings ................................... 40 



\section{Explanatory notes}

The designations employed and the presentation of the material in the Global Synthetic Drugs Assessment 2020 do not imply the expression of any opinion whatsoever on the part of the Secretariat of the United Nations concerning the legal status of any country, territory, city or area, or of its authorities, or concerning the delimitation of its frontiers or boundaries.

Countries and areas are referred to by the names that were in official use at the time the relevant data were collected.

Since there is some scientific and legal ambiguity about the distinctions between "drug use", "drug misuse" and "drug abuse", the neutral term "drug use" is used in this report. The term "misuse" is used only to denote the non-medical use of pharmaceutical drugs.
All uses of the word "drug" and the term "drug use" in this report refer to substances controlled under the three International Drug Control Conventions, and their non-medical use.

All analysis contained in this report is based on official data submitted by Member States to the UNODC through the annual report questionnaire unless indicated otherwise.

References to dollars are to United States dollars, unless otherwise stated.

References to tons are to metric tons, unless otherwise stated. 


\section{General abbreviations}

\begin{tabular}{|c|c|}
\hline AOTP & $\begin{array}{l}\text { Afghan Opiate Trade } \\
\text { Project (UNODC) }\end{array}$ \\
\hline ATS & $\begin{array}{l}\text { Amphetamine-type } \\
\text { stimulants }\end{array}$ \\
\hline BIMSTEC & $\begin{array}{l}\text { Bay of Bengal Initiative for } \\
\text { Multi-Sectoral Technical } \\
\text { and Economic } \\
\text { Cooperation }\end{array}$ \\
\hline CARICC & $\begin{array}{l}\text { Central Asian Regional } \\
\text { Information and } \\
\text { Coordination Centre For } \\
\text { Combating The Illicit } \\
\text { Trafficking Of Narcotic } \\
\text { Drugs, Psychotropic } \\
\text { Substances And Their } \\
\text { Precursors }\end{array}$ \\
\hline CNS & Central nervous system \\
\hline OVID-19 & Coronavirus disease 2019 \\
\hline DFA & $\begin{array}{l}\text { Drug Enforcement } \\
\text { Administration (United } \\
\text { States) }\end{array}$ \\
\hline DNC & $\begin{array}{l}\text { Department of Narcotics } \\
\text { Control (Bangladesh) }\end{array}$ \\
\hline ECOSOC & $\begin{array}{l}\text { United Nations Economic } \\
\text { and Social Council }\end{array}$ \\
\hline EMCDDA & $\begin{array}{l}\text { European Monitoring } \\
\text { Centre for Drugs and Drug } \\
\text { Addiction }\end{array}$ \\
\hline Europol & $\begin{array}{l}\text { European Union Agency } \\
\text { for Law Enforcement } \\
\text { Cooperation }\end{array}$ \\
\hline
\end{tabular}

EWA Early Warning Advisory on New Psychoactive Substances (UNODC)

FSPP Fentanyl Signature Profiling Program (United States)

HIV human immunodeficiency virus

INCB International Narcotics Control Board

INR Indian Rupees

ISIS/DAESH Islamic State of Iraq and the Levant

NCB Narcotic Control Bureau (India)

NDLEA National Drug Law Enforcement Agency (Nigeria)

NFLIS National Forensic Laboratory Information System (United States)

NPS New psychoactive substance(s)

PICTs Pacific island countries and territories

SMART Global Synthetics Monitoring: Analyses, Reporting and Trends Programme

STI Sexually-transmitted infections

UNODC United Nations Office on Drugs and Crime 


\section{Chemical abbreviations}

\author{
1,4-BD 1,4-butanediol \\ 2C-B 2,5-dimethoxy-4- \\ bromophenethylamine \\ 2C-C 2,5-dimethoxy- \\ 4-chlorophenethylamine \\ 2C-E 2,5-dimethoxy- \\ 4-ethylphenethylamine \\ 2C-I 2,5-dimethoxy- \\ 4-iodophenethylamine \\ 3-MMC 3-methylmethcathinone \\ 3,4-MDP-2-P/PMK 3,4-methylenedioxyphenyl- \\ 2-propanone \\ 4-AP 4-anilinopiperidine \\ 4-CEC 4-chloroethcathinone \\ 4-Cl-alpha-PVP 4-chloro-alpha- \\ pyrrolidinovalerophenone \\ 4-CMC 4-chloromethcathinone \\ 4-MEC 4-methylethcathinone \\ 5F-MMB-PICA methyl (1-(5-fluoropentyl)- \\ $1 \mathrm{H}$-indole-3-carbonyl) \\ valinate \\ AB-CHMINACA N-(1-amino-3-methyl- \\ 1-oxobutan-2-yl)-1- \\ (cyclohexylmethyl)-1H- \\ indazole-3-carboxamide \\ AB-FUBINACA $N$-[(2S)-1-amino-3-methyl- \\ 1-oxobutan-2-yl]-1-[(4- \\ fluorophenyl)methyl] \\ indazole-3-carboxamide \\ AB-PINACA (N-[(2S)-1-amino-3- \\ methyl-1-oxobutan-2-yl]-1- \\ pentyl-1H-indazole-3- \\ carboxamide
}

\author{
alpha-PVP alpha-pyrrolidino- \\ valerophenone \\ ANPP 4-anilino-N- \\ phenethylpiperidine \\ APAA alpha-phenylaceto- \\ acetamide \\ APAAN alpha-phenylaceto- \\ acetonitrile \\ bk-MDMA methylone \\ GBL gamma-butyrolactone \\ GHB gamma-hydroxybutyric \\ acid \\ NPP N-phenethyl-4-piperidone \\ LSD Iysergide \\ MAPA methyl alpha- \\ phenylacetoacetate \\ MDMA 3,4-methylenedioxy- \\ methamphetamine \\ MDPV 3,4-methylenedioxy- \\ pyrovalerone \\ NBOMe N-(2-Methoxybenzyl)- \\ 2,5-dimethoxy- \\ phenethylamine \\ NPP N-phenethyl-4-piperidone \\ P-2-P 1-phenyl-2-propanone \\ U-47700 3,4-dichloro-N-((1S,2S)-2- \\ (dimethylamino) \\ cyclohexyl)-N- \\ methylbenzamide \\ XLR-11 1-(5-fluoropentyl)-1H- \\ indol-3-yl](2,2,3,3-tetra- \\ methylcyclopropyl) \\ methanone
}




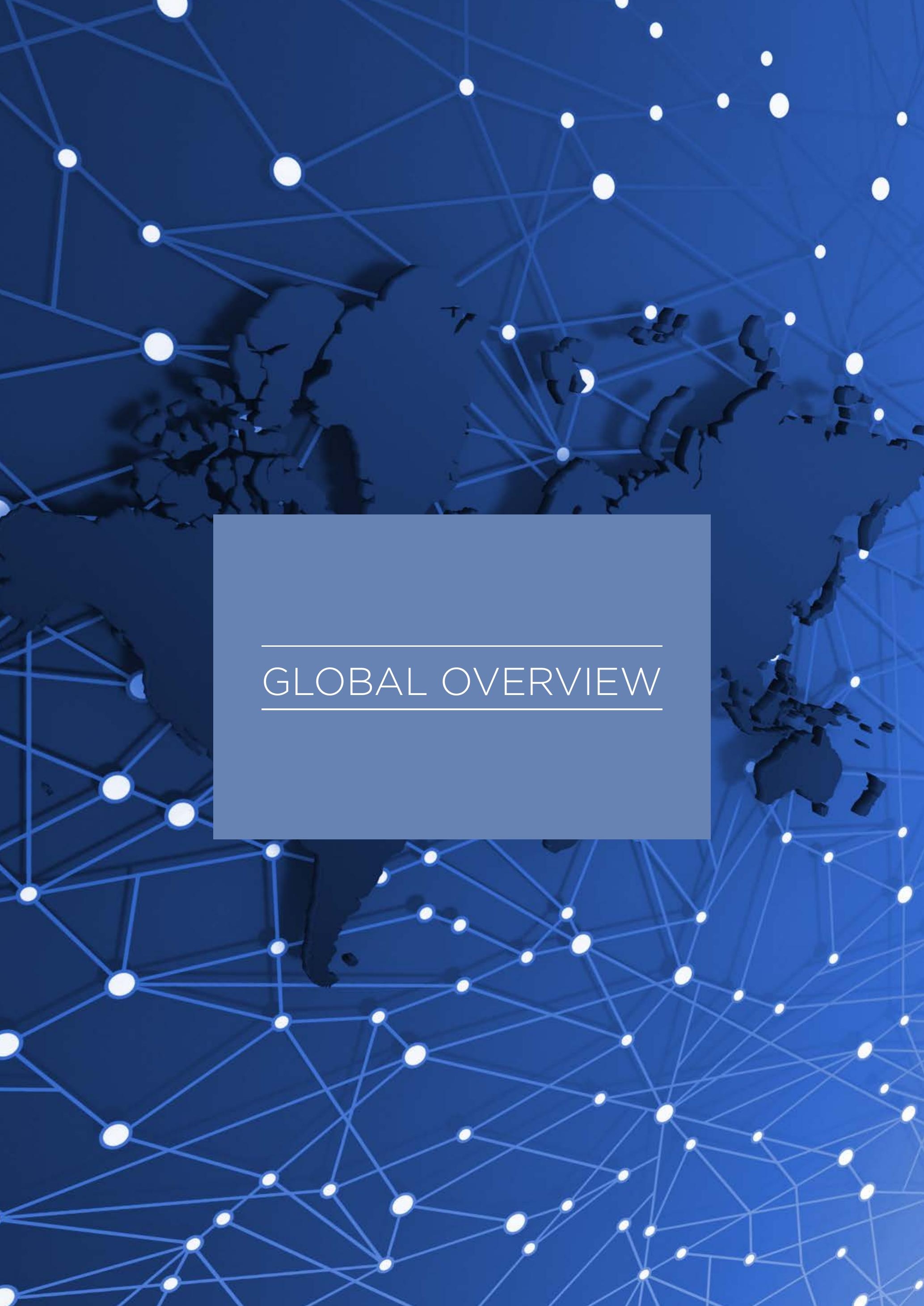




\section{OPTIONS FOR RESPONSE}

\section{Early warning systems}

In recent years, over 1,000 new psychoactive substances (NPS) have emerged on illicit drug markets. The sheer number of substances and the dynamic nature of the NPS market pose serious challenges to the timely identification and development of responses to the emerging public health threats associated with this trend. The availability of early warning systems at the national, regional and international level offer opportunities to avert potential crises through prompt information sharing among stakeholders so that the risks posed by synthetic drugs can be identified and mitigated. Such systems can represent valuable additions to the traditional monitoring of drug supply and demand indicators and facilitate awareness-raising and the communication of potential risks. At the global level, UNODC launched its Early Warning Advisory on NPS (EWA) in 2013 as an Internetbased knowledge and monitoring platform containing information on over 1,000 substances reported by more than 125 countries and territories. ${ }^{1}$

\section{International scheduling}

Drug control systems at both the national and international level have been confronted by the rapid emergence of an unprecedented number of different NPS. In response, many Member States have explored and successfully used a wide range of legislative approaches including generic, analogue and specific NPS-related legislation in addition to the individual listing of substances. Nevertheless, placing potentially harmful substances under legal control can be a lengthy process as it often requires evidence gathering and a scientific review of harms. Furthermore, differences in the control status of various substances between countries can create opportunities for the illicit manufacture and trafficking of such substances by criminal organizations. Placing the most harmful, prevalent and persistent substances under international control therefore remains an important measure for protecting human health and welfare while ensuring access to drugs for medical and scientific purposes.

${ }^{1}$ The UNODC Early Warning Advisory on NPS may be accessed at www.unodc.org/nps

\section{Enhanced precursor control}

The numerous and widespread licit uses of precursor chemicals used in the illicit manufacture of synthetic drugs in a globalized economy render control and law enforcement efforts particularly difficult. This situation is exacerbated by two significant overlapping developments in illicit manufacture: the switching from controlled to non-controlled precursors and the use of "designer" precursors. A possible approach would be to proactively control known chemicals, which have no known legitimate uses, but could potentially be used in the illicit manufacture of controlled precursors or drugs. ${ }^{2}$ With respect to the diversion of pharmaceutical preparations used in illicit drug manufacture such as ephedrine and pseudoephedrine, the strengthening of medicine legislation, monitoring systems and rational prescribing could decrease rates of diversion.

\section{Access to controlled substances for medical and scientific purposes}

Over the past years the non-medical use of opioids including fentanyl and tramadol has increased significantly. The ongoing opioid crisis, which has affected North America and parts of Africa and the Middle East, calls for a measured approach to stem the non-medical use of internationally controlled opioids and at the same time avoid a negative impact on the accessibility and availability of these opioids for pain management and palliative care. This could include estimating national requirements for controlled substances, ${ }^{3}$ and using online and electronic systems developed by various international organizations to reassess estimates and improve the efficiency of import and export procedures. ${ }^{4}$ To improve the accessibility and availability of controlled medicines in national health systems, measures such as electronic prescribing and instituting national health insurance and price-setting systems for essential medicines could be introduced.

${ }^{2}$ UNODC, "An expanding synthetic drugs market - Implications for precursor control", Global SMART Update, vol. 23 (March 2020).

${ }^{3}$ International Narcotics Control Board and World Health Organization, Guide on Estimating Requirements for Substances under International Control (2012).

${ }^{4}$ This includes the National Drug Control System (NDS) and the International Import and Export Authorization System (I2ES). 


\section{Forensic capacities}

The rapid evolution of the synthetic drug market, particularly the large number of structurally diverse NPS, has marked a turning point in forensic science practice. As a result, the work of forensic scientists to analyse and identify a large number of unknown and sometimes structurally related substances without ambiguity has become much more complex. Moreover, potent synthetic opioids are often present only in trace amounts in drugs and preparations which makes their identification even more challenging. Enhancing national forensic capacities, including ensuring the availability of chemical reference materials, screening tools, and the use of validated forensic analytical technologies and methodologies are essential.

\section{Forensic intelligence}

Samples of synthetic drugs often contain trace impurities of precursor chemicals essential to the drug manufacturing process as well as by-products resulting from side reactions. ${ }^{5}$ Through analysing the presence or absence of impurities in samples and the variations in impurity profiles, forensic science can help identify the types of precursor chemicals and synthetic routes used in the manufacture of a sample. ${ }^{6}$ This supports not only the gathering of intelligence in the context of law enforcement but also facilitates the monitoring of developments on the illicit drug market to inform drug and precursor control policies.

\section{Law enforcement capacities and detection}

The detection and identification of synthetic drugs are necessary first steps in any successful law enforcement intervention and key to the implementation of international drug control conventions at the national level. Synthetic opioids, for example, are easy to conceal and traffic, as only a few grams might be needed to produce thousands of doses. Very often, such substances are trafficked through national or international mail or express consignment shipments, making interdiction challenging due to the large number of packages that cross borders

${ }^{5}$ UNODC, Drug Characterization/Impurity Profiling: Background and Concepts.

${ }^{6}$ United Nations International Drug Control Programme, "Drug characterization/impurity profiling, with special focus on methamphetamine: recent work of the United Nations International Drug Control Programme., Bulletin on Narcotics, vol. LI, No. 1 and 2 (1999), p. 103.

${ }^{7}$ Pierre Esseiva and others, "Forensic Drug Intelligence: An Important Tool in Law Enforcement", Forensic Science International, vol. 167, No. 2-3 (2007), pp. 247-254. every day. Modern analytical technologies offer improved field identification capacity and limit the exposure of front-line officers to the potentially hazardous effects of handling some of these substances. Knowledge of modus operandi, synthesis methods, precursors and overall trafficking patterns, as well as cross-border intelligence sharing in real time, allow for better analysis capacity and more complex investigations. With the Internet and darknet being increasingly used as platforms for supplying synthetic drugs, investments into strengthening the cybercrime capacities of law enforcement agencies are also an important consideration.

\section{International and regional cooperation}

Systematic international collaboration on a global level among all actors is crucial to addressing the challenges posed by an expanding synthetic drugs market. Such cooperation is fundamental to bridging information, capacity and resource gaps in order to address the synthetic drug problem. Tools such as the UNODC Early Warning Advisory on NPS and the United Nations Toolkit on Synthetic Drugs ${ }^{8}$ also provide Member States and other stakeholders with a wide range of electronic resources to obtain information and address key challenges presented by synthetic drugs.

\section{Public-private partnerships}

Strong public-private partnerships are essential to address the challenges posed by NPS and enable an effective precursor control regime. The continuing emergence of NPS creates the need for commercially available testing equipment, toxicology screens and reference materials, as well as forensic and chemical expertise, to help forensic laboratories and law enforcement identify these new substances and verify their analysis. ${ }^{9}$ In addition, Governments might want to consider collaborating with academia and support the scientific research needed to generate evidence for potential national and international controls. In terms of the precursors used in illicit drug manufacture, private enterprises involved in the licit production, distribution, trade, financing and shipping of chemicals wield great influence and hold significant potential to be able to identify vulnerabilities in their supply chains and prevent the diversion of their products into illicit channels. ${ }^{10}$

\footnotetext{
${ }^{8}$ The United Nations Toolkit on Synthetic Drugs may be accessed at syntheticdrugs.unodc.org/

'UNODC, "The growing complexity of the opioid crisis", Global SMART Update, vol. 24 (September 2020).

${ }^{10}$ UNODC, "An expanding synthetic drugs market - Implications for precursor control", Global SMART Update, vol. 23 (March 2020).
} 


\section{Health responses}

A range of interventions and policies is needed to reduce risks to public health including, but not limited to, national drug prevention systems ${ }^{11}$ and the training and sensitization of first responders. One important aspect is to scale up overdose prevention interventions and train first responders in overdose management, for example, the use of naloxone for the reversal of opioid overdose. Information sharing and promoting evidenced-based practices in terms of the spectrum of treatment and care interventions are essential to reduce the use of synthetic drugs including substandard and falsified medicines. The removal of stigma through addressing stigmatizing attitudes to drug use and drug use disorders could also improve access to treatment, for example of opioid use disorders. ${ }^{12}$
${ }^{11}$ UNODC and WHO, International Standards on Drug Use Prevention, second updated edition (March 2018).
${ }^{12}$ James D. Livingstone and others, "The effectiveness of interventions for reducing stigma related to substance use disorders: a systematic review", Addiction, vol. 107, No. 1 (2012), pp. 39-50. 


\section{IMPACT OF THE COVID-19 PANDEMIC ON THE SALE OF SYNTHETIC DRUGS}

The onset of the COVID-19 pandemic in late 2019 has brought about profound and wide-ranging effects on a global level. In an effort to contain the pandemic, governments around the world have closed non-essential parts of the economy and imposed border, travel and mobility restrictions which have had a detrimental effect on the global economy and many aspects of daily life. Although the synthetic drugs market is globally interconnected, the impact of the pandemic has proved to be less severe than initially expected. One major reason for this seems to be the high level of flexibility and adaptability shown by organized crime groups to change their business models and trafficking methods in response to market shortages and constraints. On the other hand, stringent social distancing policies and economic hardship may have had an adverse impact on localized (street level) supply and demand patterns. While it is likely that law enforcement operational capacities against illicit drug flows may be focused elsewhere or even lessened during the pandemic, the trafficking of drugs by container vessels or commercial air freight seems to have continued without major disruption. Drug trafficking by post and parcel services also seems to have continued with some regions seeing increases in volumes. ${ }^{13,14}$

While it was expected that the lockdown in China would disrupt the supply of precursor chemicals for methamphetamine manufacture, vessels continued to ship large numbers of containers from East Asia to North America and Europe. As a result, smuggling opportunities within container traffic remained a viable and available transport option for illicit goods such as precursor chemicals. ${ }^{15}$ Another mode of transport that increased significantly in East and South-East Asia was rail freight, as evidenced by greater volumes of Chinese rail freight across Central Asian and South-Eastern European rail networks in the first months of the pandemic. ${ }^{16}$ Similarly, media reports suggested potential disruptions to the supply of precursor chemicals for the illicit manufacture of fentanyl in Mexico,

\footnotetext{
${ }^{13}$ UNODC, Synthetic Drugs in East and South-East Asia: Latest Developments and Challenges (May 2020).

${ }^{14}$ UNODC, "COVID-19 and the drug supply chain: from production and trafficking to use", Research Brief (May 2020).

${ }^{15}$ Global Initiative Against Translational Organized Crime, Jason Eligh, Crisis and opportunity, Impacts of the coronavirus pandemic on illicit drug markets (May 2020). Available at https://globalinitiative.net/wpcontent/uploads/2020/05/Crisis-and-Opportunity-Jason-ElighGITOC.pdf

${ }^{16} \mathrm{Ibid}$.
}

but quantities seized at United States borders in early 2020 did not change significantly compared to the previous year. ${ }^{17,18}$ A possible consequence of the pandemic, however, is the risk that heroin shortages caused by potential disruptions to trafficking routes from Latin America and South-West and South-East Asia may lead to the adulteration or substitution of heroin with cheaper and more harmful synthetic opioids with potentially serious adverse health consequences for users, especially if potent opioids such as fentanyl and its analogues are used for that purpose. ${ }^{19}$ With regard to methamphetamine, some reports indicate that initial disruptions in the supply of precursor chemicals to Mexico may have led to a rise in the price of methamphetamine sold in the United States. Nevertheless, total amounts of methamphetamine seized up to July 2020 remain higher compared to the same period in 2019, and disruptions, if any, appear to have been short-lived. ${ }^{20,21}$

In Europe, no disruption in synthetic drug manufacture has been noted in Belgium or the Netherlands, as evidenced by the number of illicit laboratories dismantled and dump sites reported. ${ }^{22}$ However, the global demand for synthetic drugs used in recreational settings appears to have decreased due to the closure of bars and nightclubs and the cancellation of music festivals, leading to a drop in wholesale prices of more than 20 per cent. ${ }^{23}$ While the trafficking of "ecstasy" tablets from Western and Central Europe to the Caribbean and Central and South America has been disrupted due to a halt in air passenger transportation, possibly leading to higher retail prices in some countries, drug trafficking by commercial air freight and shipping container vessels appears to be continuing, as evidenced by the comparatively

\footnotetext{
${ }^{17}$ UNODC, "COVID-19 and the drug supply chain: from production and trafficking to use", Research Brief (May 2020).

${ }^{18}$ Keegan Hamilton, "Sinaloa Cartel Drug Traffickers Explain Why Coronavirus Is Very Bad for Their Business", Vice (23 March 2020). Available at www.vice.com/en ca/article/bvgazz/sinaloa-cartel-drugtraffickers-explain-why-coronavirus-is-very-bad-for-their-business

${ }^{19}$ UNODC, "The growing complexity of the opioid crisis", Global SMART Update, vol. 24 (October 2020).

${ }^{20}$ United States, Customs and Border Protection, CBP Enforcement Statistics Fiscal Year 2019, 2019. Available at www.cbp.gov/newsroom/ stats/cbp-enforcement-statistics-fy2019

${ }^{21}$ United States, Customs and Border Protection, CBP Enforcement Statistics Fiscal Year 2020, 2020. Available at www.cbp.gov/newsroom/ stats/cbp-enforcement-statistics

${ }^{22}$ European Monitoring Centre for Drugs and Drug Addiction, EU Drug Markets Impact of COVID-19 (May 2020).

${ }^{23}$ Ibid.
} 
large quantities of "ecstasy" seized recently on arrival in some South American countries.

While governments are clearly attempting to address the economic, health and social problems caused by the pandemic with massive investment programmes, such reallocation of public resources may jeopardize recent efforts to strengthen drug prevention and treatment programmes. A reduction in resources to these programmes may render those at the margins of society even more vulnerable and undermine drug demand reduction efforts. ${ }^{24}$ 


\section{TRENDS IN TRAFFICKING AND USE OF SYNTHETIC DRUGS}

The synthetic drugs market is unique due to the simplicity, flexibility and scalability of manufacture; the availability of a wide variety of precursors and synthetic routes; the existence of a huge globalized, licit chemical and pharmaceutical industry using similar substances and production methods; and its independence from cultivation seasons and environmental conditions. Consequently, the affordability, availability and purity of synthetic drugs have increased, as have the health harms associated with their use. The synthetic nature of these substances also allows traffickers to market them in increasingly diverse forms of presentation: as powders, tablets, capsules, liquids, impregnated blotter stamps, herbal material, sprays and in crystalline form. Synthetic drugs may therefore be ingested, smoked, inhaled, vaped, insufflated, injected, applied sublingually or used as patches, suppositories, eye drops or nasal sprays.

The sheer number of more than 1,000 new psychoactive substances (NPS) which have emerged on illicit drug markets in recent years poses a serious challenge to users, health and emergency services and drug control. In addition, synthetic drugs are not always readily recognizable as such as they may be presented as legitimate

Figure 1. Global quantities of amphetaminetype stimulants seized, 2013-2018

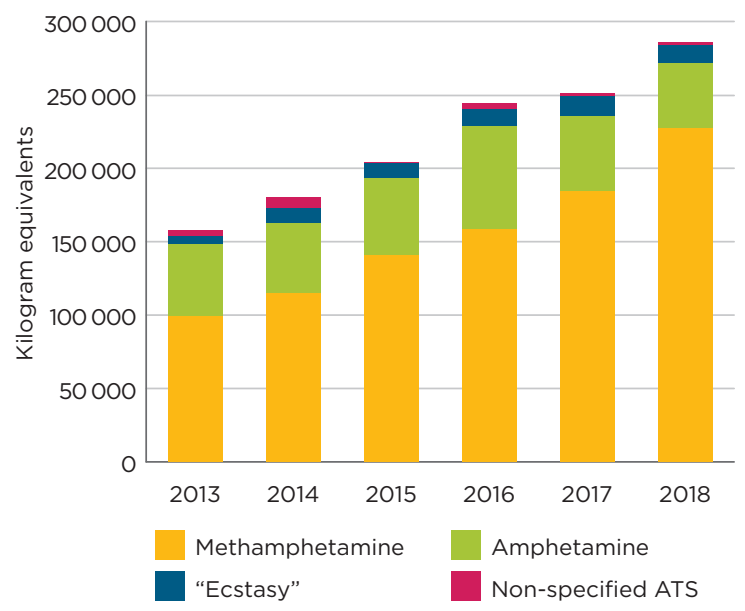

Sources: UNODC, responses to the annual report questionnaire. Amphetamine data in 2018: Aggregate quantities seized; UNODC (2019), Subcommission on Illicit Drug Traffic and Related Matters in the Near and Middle East, Fifty-fourth session -Country Report: United Arab Emirates and Saudi Arabia. Individual seizures: Jordan Armed Forces - Arab Army (March 2018 to December 2018). pharmaceuticals. Neither drug users nor traffickers have the means to differentiate between such a large number of substances, and drug control agencies and forensic laboratories need to invest continuously to keep up to date with new developments and trends. Patterns of use have also evolved with polydrug use on the increase. Furthermore, international criminal organizations are suspected of exchanging knowledge across continents on manufacturing and concealment methods as opportunities for trafficking offered by the darknet and the use of cryptocurrencies grow.

\section{Methamphetamine: a dynamic and growing market}

The methamphetamine market has expanded globally during the past few years with seizures more than doubling from 100 tons in 2013 to 228 tons in 2018. The increase in quantities seized, together with falling retail prices and increased purity, point to a dynamic and growing market for the drug. North America and East and South-East Asia remain the two main hubs for methamphetamine trafficking. In 2018, the largest seizures in North America were reported by the United States and Mexico, and in East and South-East Asia, by China and Thailand. In recent years methamphetamine trafficking has expanded to other regions with increasing quantities seized in countries in South-West Asia, South Asia, Central Asia and Transcaucasia, the Near and Middle East, Southern Africa, West Africa and Europe.

Methamphetamine is trafficked extensively within North America and East and South-East Asia, and to a lesser extent, Oceania. In addition, methamphetamine from North America is increasingly being trafficked to other parts of the world such as Europe, East and SouthEast Asia, and Oceania. Moreover, significant quantities of precursors chemicals for methamphetamine manufacture are trafficked from East and South-East Asia to Oceania.

While extensive methamphetamine manufacture has been reported in North America by Mexico and the United States as well as in East and South-East Asia, specifically the Golden Triangle, manufacture seems to have expanded in other regions including South-West Asia, Southern Africa, West Africa, and Western and Central Europe. In addition, organized criminal groups 
Figure 2. Regional distribution of methamphetamine quantities seized, 2013-2015 and 2016-2018

2013-2015: 356 tons

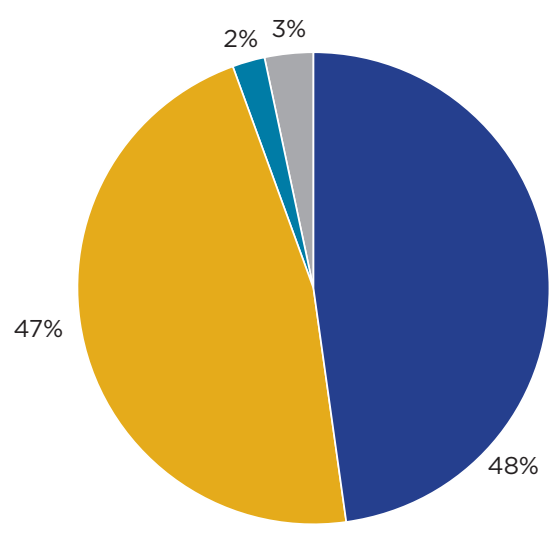

North America
East and South-East Asia, Oceania
2016-2018: 571 tons

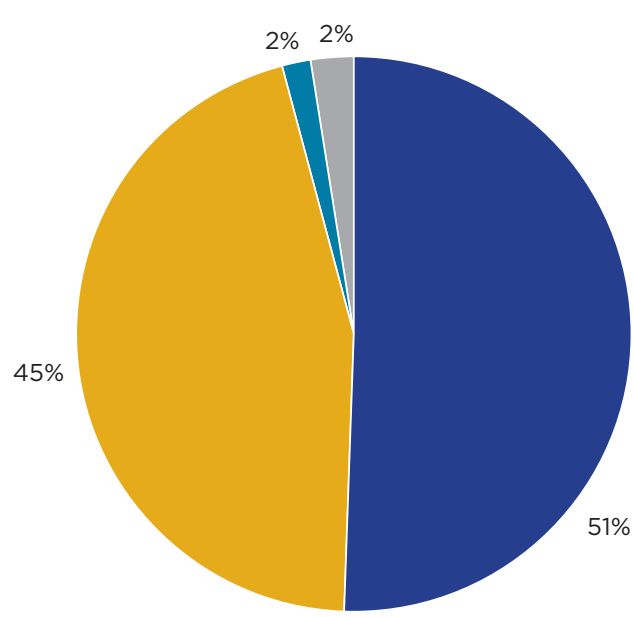

South-West Asia

Other regions

Source: UNODC, responses to the annual report questionnaire.

from Mexico seem to be involved in large-scale methamphetamine manufacture in Belgium and the Netherlands. Increases in quantities of crystalline methamphetamine seized and its higher purity, which is associated with higher health risks for users, has led to more severe negative health implications, growing demand for treatment and more methamphetamine-related deaths in some countries.

\section{Amphetamine: the growing impact of "captagon"}

Over the 2013-2018 period, global annual quantities of amphetamine seized fluctuated between 45 and 71 tons. However, fluctuations in quantities were mainly related to countries in the Near and Middle East, which have the largest amphetamine ("captagon") ${ }^{25}$ market, whereas

\footnotetext{
${ }^{25}$ Tablets contain mostly amphetamine and caffeine.
}

Figure 3. Regional distribution of amphetamine quantities seized, 2013-2015 and 2016-2018

\section{3-2015: 149 tons}

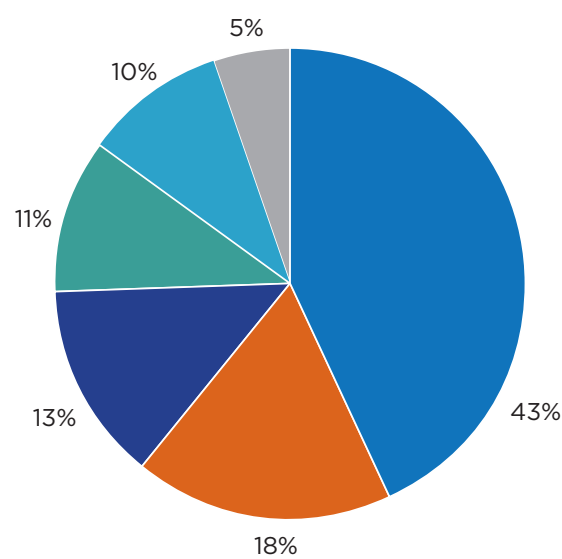

2016-2018: 166 tons

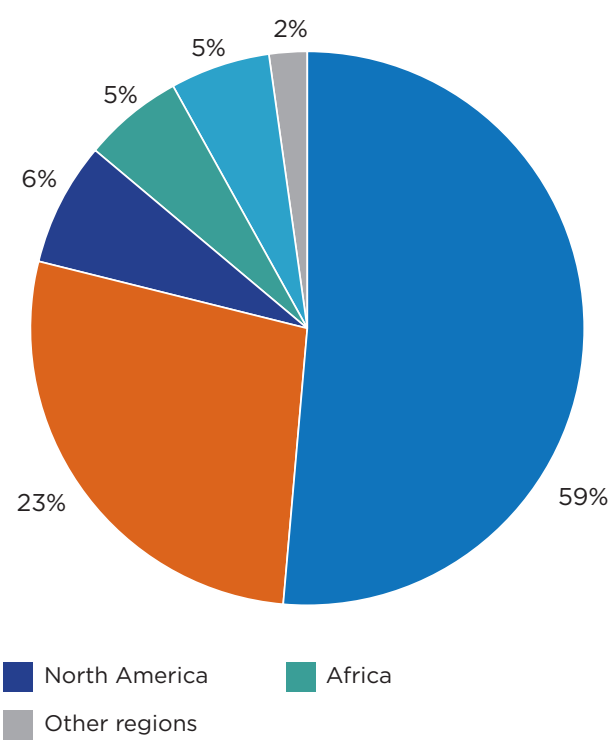

Source: UNODC, responses to the annual report questionnaire. 
Figure 4. Total amphetamine seizures reported worldwide, 2013-2018

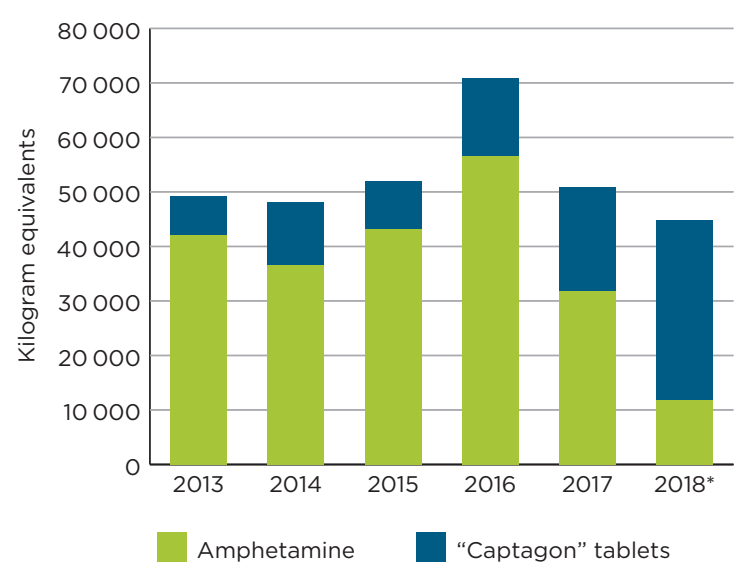

Source: UNODC, responses to the annual report questionnaire. *Aggregate quantities seized: UNODC (2019), Subcommission on Illicit Drug Traffic and Related Matters in the Near and Middle East, Fifty-fourth session - Country Report: United Arab Emirates and Saudi Arabia. Individual seizures: Jordan Armed Forces - Arab Army (March 2018 to December 2018).

seizures in other regions have remained relatively stable. At the regional level, the largest annual quantities of amphetamine seized continue to be reported by countries in the Near and Middle East, particularly Jordan, Lebanon, Saudi Arabia and the United Arab Emirates. Most of the amphetamine seized in the region is reported to have originated in Lebanon and the Syrian Arab Republic. Instability and conflicts in the Near and Middle East seem to have nurtured the manufacture and trafficking of "captagon" with both origin and destination typically being within the region, although "captagon" shipments sometimes transited other regions including Europe.

An increase in amphetamine seizures was reported in Europe over the 2013-2018 period where in 2018, for the first time, more "captagon" tablets were seized than any other form of amphetamine. Europe has also seen an increase in amphetamine use in recent years. Most of the global supply of amphetamine is manufactured in the Near and Middle East and Europe, partly for domestic use and partly for trafficking to other countries. Similar to methamphetamine, retail prices for amphetamine decreased globally during this period, while its purity increased.

\section{An expanding market for "ecstasy"}

Sharp increases in the quantities of "ecstasy" seized have been reported in recent years, with global seizures more than doubling from 5 tons in 2013 to almost 12 tons in 2018. Europe dominates global seizures in terms of quantities, followed by East and South-East Asia, Oceania and North America. The trafficking of "ecstasy" continues to expand with non-controlled precursor chemicals being used for its manufacture and increased quantities of seizures being reported by countries in Central Asia and Transcaucasia, North Africa, Southern Africa, Central America and the Caribbean. Large-scale manufacture of "ecstasy" has been reported in Europe,

Figure 5. Regional distribution of seized quantities of "ecstasy", 2013-2015 and 2016-2018

2013-2015: 25 tons

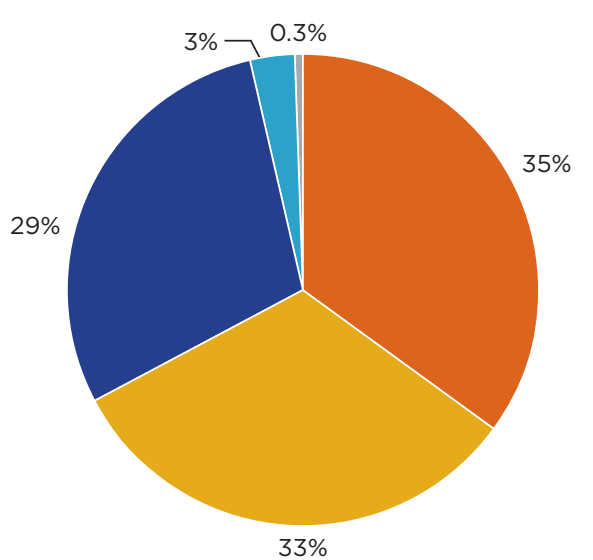

Europe

East and South-East Asia, Oceania

Central America, South America, Caribbean
2016-2018: 37 tons

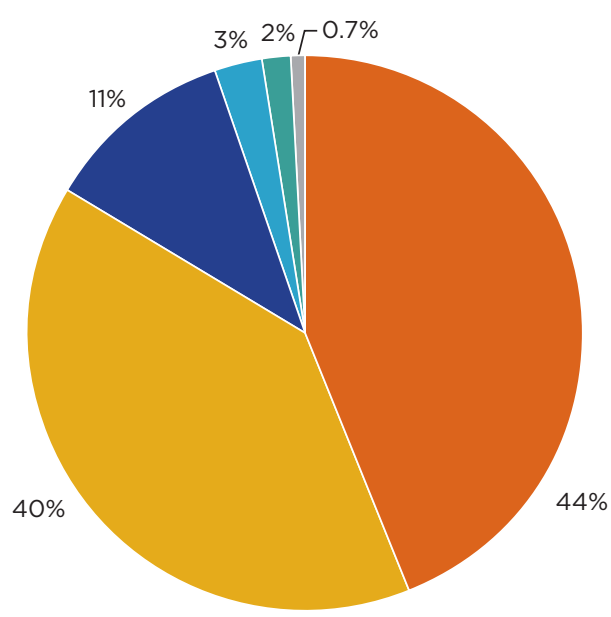

North America

Africa

Other regions 


\section{Box 1. Environmental impact of illicit synthetic drugs manufacture}

Synthetic drug manufacture has a large negative environmental impact as a result of the waste created during the manufacturing process. Waste encountered at clandestine laboratories, as well as the safe handling, storage and disposal of seized chemicals, presents unique problems to law enforcement and regulatory authorities. ${ }^{a}$ Manufacturing $1 \mathrm{~kg}$ of amphetamine, for example, is estimated to generate between 20 and $30 \mathrm{~kg}$ of waste. ${ }^{b}$ Moreover, the illicit manufacture of alternative precursors also produces a significant amount of waste which is additional to the manufacture of the synthetic drug itself. Criminal organizations dispose of waste through burning, dumping it in the countryside or leaving it in abandoned residences. If this waste finds its way into the soil or water, it can have detrimental effects on the flora and fauna, as well as potentially on the quality of drinking water. Between 2015 and 2017, almost 660 illicit dump sites were notified to authorities in Belgium (68) and the Netherlands (591). ${ }^{c}$

Clandestine laboratories are often found in locations where the immediate management of seized chemicals is required in order to reduce risks to people and the environment. However, appropriate waste management infrastructure and the necessary technical support may not always be available, particularly in remote locations. ${ }^{d}$ With the expansion of the synthetic drug market, the associated health and environmental risks, as well as the considerable costs associated with dismantling clandestine laboratories, are expected to grow.

Minimum estimated cost of dismantling/cleaning up synthetic drug production, storage and waste dump sites, in Belgium and the Netherlands, 2016

\begin{tabular}{|l|c|c|}
\hline Country & Number of sites & Total cost (€) \\
\hline Belgium & 42 & $1,401,634$ \\
\hline Netherlands & 322 & $4,368,294$ \\
\hline Total & 364 & $5,769,928$ \\
\hline
\end{tabular}

Source: Claessens, M., Hardyns, W., Vander Laenen, F. and Verhaeghe, N., "An analysis of the costs of dismantling and cleaning up synthetic drug production sites in Belgium and the Netherlands", background paper for this report, European Monitoring Centre for Drugs and Drug Addiction, Lisbon, 2019.

aNODC, Guidelines for the Safe Disposal of Chemicals used in the Illicit Manufacture of Drugs (September 2011).

${ }^{b}$ Europol, EU Manual on Illicit Synthetic Drugs/NPS Production, Europol, The Hague, 2019.

cEuropean Monitoring Centre for Drugs and Drug Addiction and Europol, EU Drug Markets Report 2019.

aUNODC, Illustrated Guide for the Disposal of Chemicals used in the Illicit Manufacture of Drugs (October 2017).

mainly in Belgium and the Netherlands, from where it is trafficked to consumer markets globally. In addition, first-time "ecstasy" manufacture has been reported in Southern Africa with clandestine laboratories dismantled in South Africa, and in South America manufacture of "ecstasy" was reported that also entailed the synthesis of MDMA and/or MDA.

While "ecstasy" was previously a rather niche drug, it is now used by a broader range of people in mainstream recreational nightlife settings. Products being sold as "ecstasy" have become increasingly diversified, with some tablets containing little or no 3,4-methylenedioxymethamphetamine (MDMA) and others having extremely high MDMA content, as well as being sold in powder and crystalline form. As with other synthetic drugs, there is a global tendency towards purer and higher dose "ecstasy" products sold at the retail level. Whereas in the past a typical "ecstasy" pill often contained no more than 50-80 mg of MDMA, ${ }^{26}$ high dose "ecstasy" tablets nowadays can consist of more than $300 \mathrm{mg}$ of MDMA and their use has been linked to severe adverse health consequences. As a result, the health risks associated with the use of "ecstasy" have risen significantly.

\footnotetext{
${ }^{26}$ European Monitoring Centre for Drugs and Drug Addiction, Recent changes in Europe's MDMA/ecstasy market - Results from an EMCDDA trendspotter study, Rapid Communication Luxembourg, Publications Office of the European Union, 2016.
} 


\section{New psychoactive substances: expansion of synthetic opioids and benzodiazepine-type new psychoactive substances}

New psychoactive substances (NPS) are substances of abuse that have similar effects to drugs under international control. Up to August 2020, 125 countries and territories reported the emergence of more than 1,000 individual NPS. The NPS situation globally is characterized by a marked heterogeneity as 87 countries and territories have reported the emergence of fewer than 100 NPS while 10 countries have reported more than 300 substances. Up to August 2020 and considering all NPS reported since monitoring began in 2008 , stimulants constitute the largest group of NPS at 35 per cent, followed by synthetic cannabinoid receptor agonists at 29 per cent. However, while the market share of stimulants reported increased slightly between 2018 and 2019, the market share and number of synthetic cannabinoid receptor agonists reported decreased at the same time, indicating a decrease in the diversity of substances within this effect group. Manufacture of NPS has been reported from countries in Europe, East and South-East Asia, Oceania, South Asia, South America, Southern Africa and most recently from Central Asia and Transcaucasia.

While the prevalence of use of NPS is rather low among the general population, the use of stimulants, synthetic cannabinoid receptor agonists, synthetic opioids and sedatives/hypnotics (mostly benzodiazepine-type NPS) is more common in high-risk drug users and marginalized groups such as people who inject drugs, the homeless and prison populations. It is likely that the health harms associated with the use of NPS have increased with the emergence of very potent substances which have the potential to lead to unintentional overdose events including fatalities. The purity and composition of products containing NPS are often unknown, which places users at high risk as evidenced by hospital emergency admissions and deaths associated with NPS.

Interactions between the NPS market and traditional drugs have intensified with NPS being sold alongside or in mixtures with other drugs. In Central and South America for example, NBOMe compounds continue to be sold as LSD, and samples seized as 2C-B often contain other substances, such as ketamine, amphetamine, MDMA or a range of NPS.

The number of synthetic opioids and sedatives/hypnotics appears to be growing and is associated with an increasing number of emergency-room cases and deaths. Over 80 different synthetic opioids have been reported to UNODC since 2009, with fentanyl analogues being the dominant and fastest growing subgroup among NPS with opioid effects. However, the number of non-fentanylrelated synthetic opioids reported annually has also increased steadily in recent years, and in 2019 NPS with opioid effects reported to UNODC belonged to eight different chemical classes, indicating a growing chemical diversity of NPS with opioid effects on the market. ${ }^{27}$

${ }^{27}$ UNODC, “The growing complexity of the opioid crisis", Global SMART Update, vol. 24 (October 2020)

Figure 6. New psychoactive substances by effect group, 2009-2019

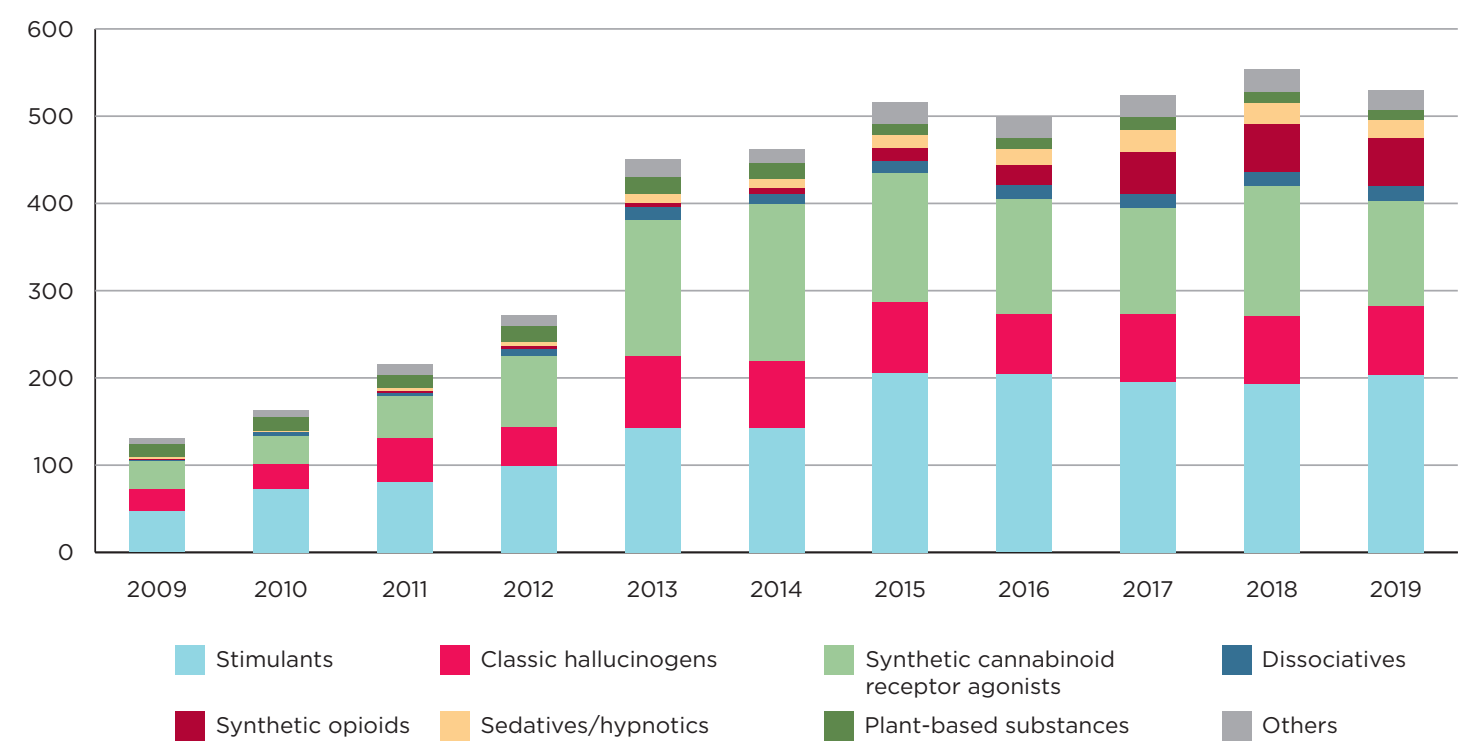

Source: UNODC, Early Warning Advisory on New Psychoactive Substances. 
Figure 7. Distribution of new psychoactive substances by effect group, in 2015 and 2019
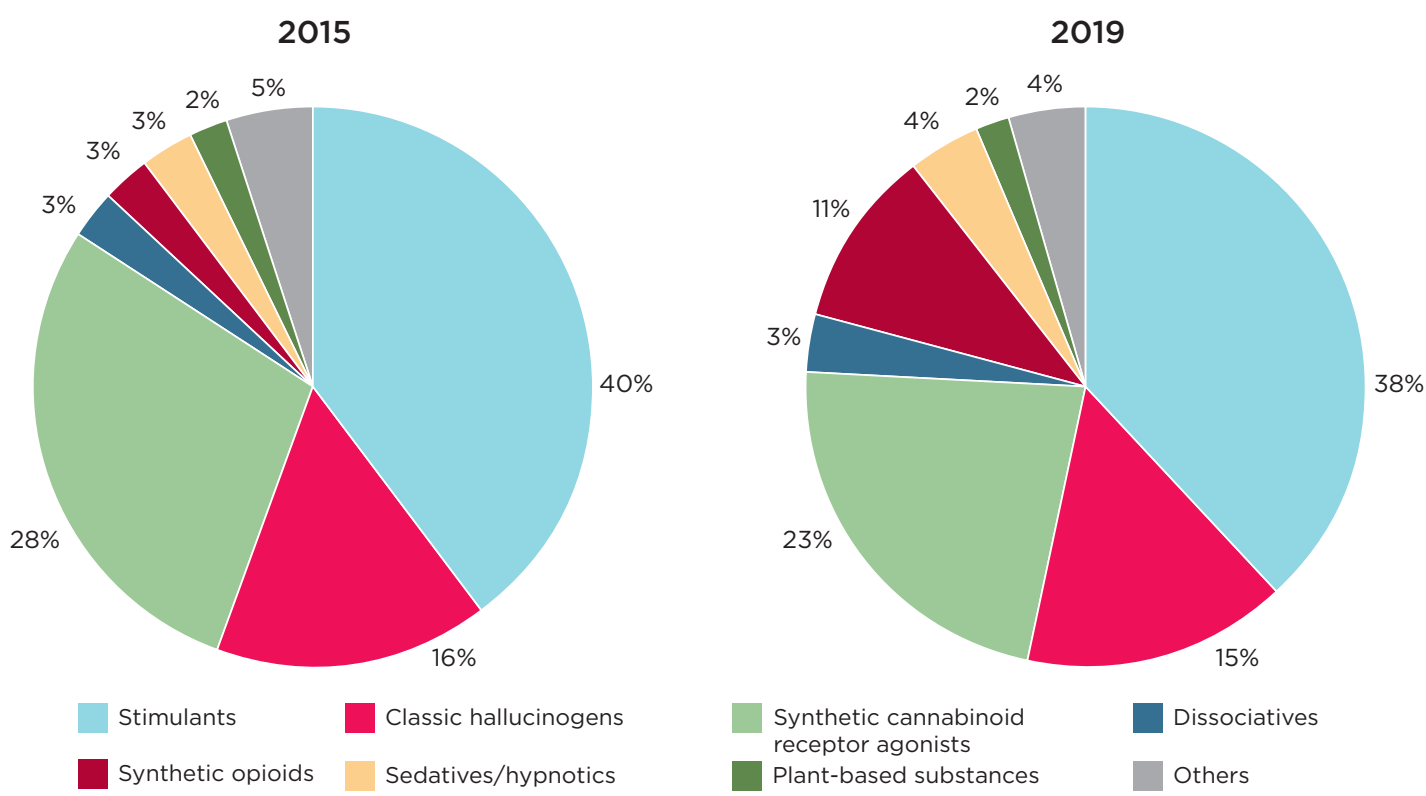

Source: UNODC, Early Warning Advisory on New Psychoactive Substances.

Synthetic opioids have been found in blotters and in herbal smoking mixtures which may pose an elevated risk of overdose as the form of presentation does not give any indication that they contain potent opioids.

The number of NPS with sedative/hypnotic effects has also increased with over 30 substances, mostly benzodiazepine-type NPS, reported up to August 2020. Benzodiazepine-type NPS are often sold at very low prices, sometimes mimicking medicines in shape, with variable dosages of active ingredients, possibly containing contaminants, as well as highly potent synthetic opioids. There have also been reports from Europe of such substandard and falsified medicines being produced by the same organized crime groups that manufacture and/or traffic synthetic drugs, such as MDMA, LSD and ketamine. Given their sedative/hypnotic nature, their use alone or in combination with other drugs may impair driving capabilities. ${ }^{28}$ Etizolam, ${ }^{29}$ flualprazolam ${ }^{30}$ and flubromazolam were the benzodiazepine-type NPS most frequently reported to UNODC in the context of driving under the influence of drugs. In most cases, other drugs such as cannabis, cocaine, MDMA, amphetamine, methamphetamine and prescription benzodiazepines (e.g., alprazolam, clonazepam, diazepam or lorazepam) were also detected.

${ }^{28}$ UNODC, Current NPS Threats, vol. II (January 2020).

${ }^{29}$ Etizolam has been under international control as of November 2020. ${ }^{30}$ Flualprazolam has been under international control as of November 2020.

\section{The non-medical use of opioids is expanding: fentanyl and tramadol}

Over the past years there have also been significant increases in the non-medical use of opioids including fentanyl and tramadol. Over the period 2013 to 2018, global tramadol seizures ranged from 9 to 125 tons with the largest quantities being seized in West and Central Africa, North Africa, and the Near and Middle East. Increasing quantities have also been reported from Central Asia and Transcaucasia. Almost half of all countries in Africa have reported non-medical use, seizures or trafficking of tramadol. The non-medical use of tramadol has become a growing concern in the region, particularly among men, young people and manual or construction workers. Tramadol seized in the Near and Middle East seems to be mostly trafficked from North Africa and South Asia to the region for domestic use.

The trafficking and non-medical use of fentanyl and its analogues continue to pose serious threats to drug control and public health, especially in North America, where deaths involving fentanyl and its analogues remain a significant concern. Global seizures of fentanyl grew from $25 \mathrm{~kg}$ in 2014 to 3 tons in 2018. Most significantly, quantities of fentanyl seized in North America have grown sixfold from about 0.4 tons in 2016 to 2.9 tons in 2018, mainly in the United States. Information from law enforcement suggests that fentanyl in the United States is primarily sourced from China or Mexico and is often trafficked into the country in the form of powders or falsified prescription tablets. Increasing quantities of fentanyl have also been reported by countries in Europe and East and South-East Asia. 


\section{TRENDS IN THE MANUFACTURE OF SYNTHETIC DRUGS}

The manufacture of synthetic drugs requires the conversion of precursor chemicals into the finished drug. This conversion can be effected in one or more steps and can be mediated by a variety of chemicals and reagents. As a result, the illicit manufacture of amphetaminetype stimulants (ATS) such as 3,4-methylenedioxymethamphetamine (MDMA), amphetamine or methamphetamine is highly flexible. This is illustrated by the fact that 14 of the 22 precursor chemicals listed in Table I of the United Nations Convention against Illicit Traffic in Narcotic Drugs and Psychotropic Substances of 1988 ("1988 convention") are precursors for amphetamine-type stimulants (ATS) and that the total number of precursor chemicals in Table I of the 1988 convention has increased by eight ( 57 per cent) since 2014, including the 2020 decision to place methyl alpha-phenylacetoacetate (MAPA) under international control.

A decade ago, the primary precursors used for the manufacture of methamphetamine were pseudoephedrine and ephedrine. These substances are widely used in pharmaceuticals and thus their diversion from licit manufacture, either in bulk form or as pharmaceutical preparations, was the main source of precursors for illicit manufacture. The other main precursor chemicals used for the manufacture of amphetamine and methamphetamine are 1-phenyl-2-propanone (P-2-P) and its precursor phenylacetic acid. Since then, there have been two significant overlapping developments in precursor control: a switch from controlled to non-controlled precursors and the use of "designer" precursors.

Apart from international scheduling decisions, these developments are influenced by a multitude of factors including different national precursor legislation and enforcement capabilities, discrepancies in precursor controls between neighbouring countries and the increasing versatility among illicit manufacturers to switch between alternative precursors and synthetic routes. These developments are not linear in nature however, and illicit manufacturers have switched back and forth between controlled, non-controlled and "designer" precursors. While the use of non-controlled precursors is not a recent development, the emergence of a large number of "designer" precursors in recent years is of major concern to the international community. ${ }^{31}$

"Designer" precursors can be classified into two main groups: "masked" precursors and chemical intermediates. "Masked" precursors are chemical substances specifically designed to disguise controlled precursors from which

${ }^{31}$ UNODC, "An expanding synthetic drugs market - Implications for

Figure 8. Changes to tables of the United Nations Convention against Illicit Traffic in Narcotic Drugs and Psychoactive Substances of 1988 since 2010

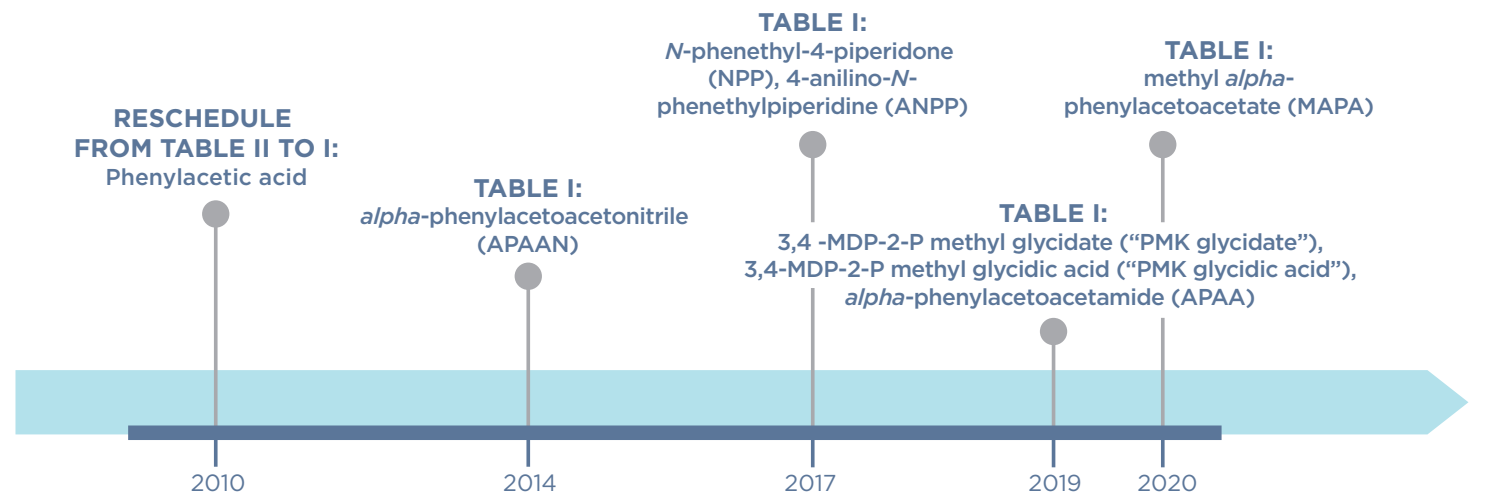

Source: United Nations, Tables of the United Nations Convention against Illicit Traffic in Narcotic Drugs and Psychotropic Substances of 1988, as at as at 4 March 2020, Commissions Resolutions and Decisions Database. Available at www.unodc.org/rddb/ 
controlled precursors can easily be obtained. They may include derivatives of controlled precursors with varying degrees of complexity. Examples include derivatives of phenylacetic acid and P-2-P such as methyl phenylacetate, P-2-P bisulfite adduct and P-2-P methyl glycidate. Chemical intermediates on the other hand are chemical substances that are produced during the manufacture of drugs from precursors but are not typically isolated. When isolated, these chemical substances can themselves be considered precursors. Examples of these chemical intermediates include alpha-phenylacetoacetonitrile (APAAN), methyl alpha-phenylacetoacetate (MAPA) and chloroephedrine.

Figure 9. Evolution of the range of precursors and plants used in the illicit manufacture of amphetamine and methamphetamine

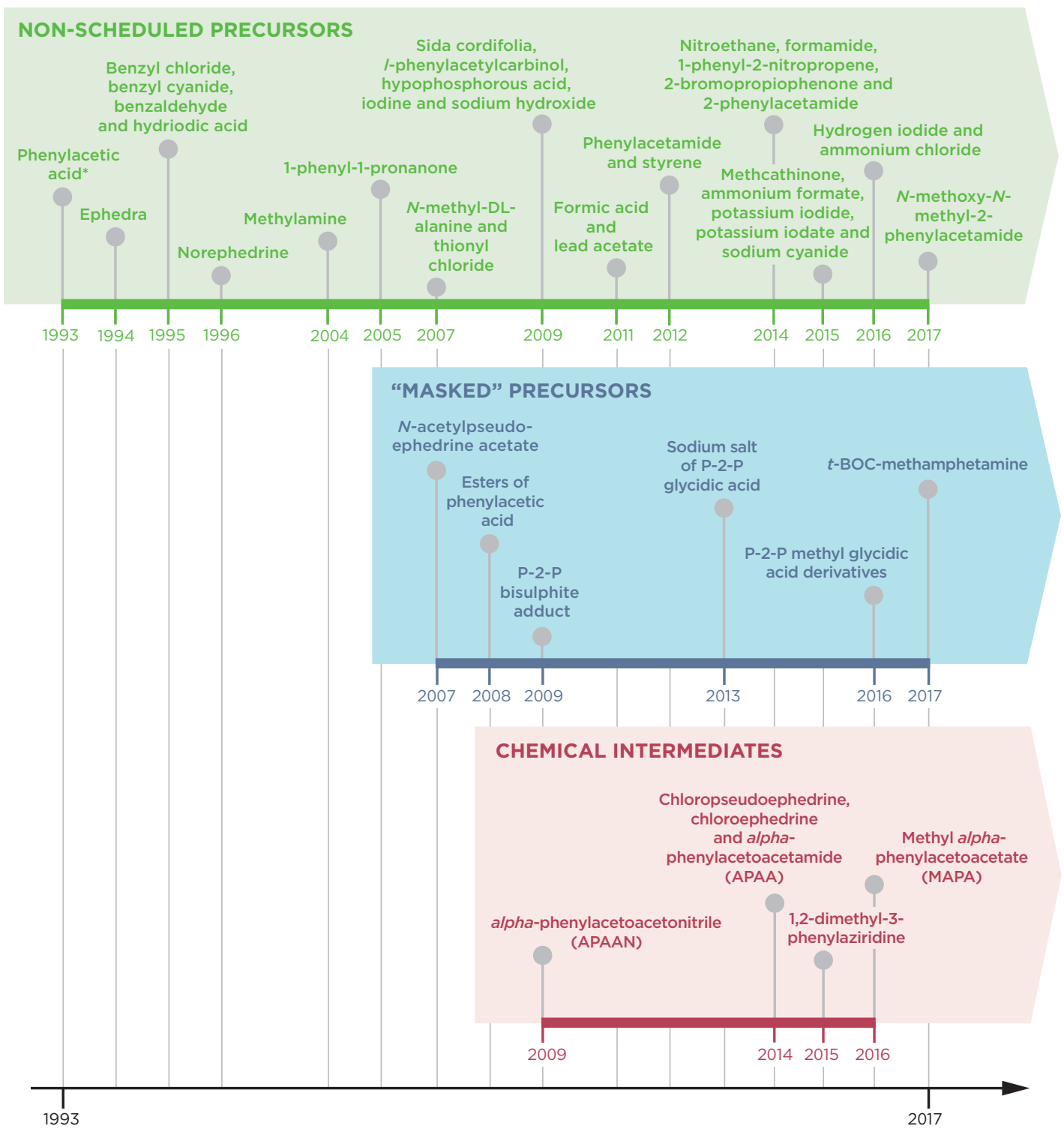

Source: International Narcotics Control Board, various editions of the annual report on Precursors and chemicals frequently used in the illicit manufacture of narcotic drugs and psychotropic substances.

Note: The years indicate when a precursor was documented as a significant change or innovation, not necessarily when it was first used.

${ }^{*}$ Common amphetamine/methamphetamine precursors including ephedrine, pseudoephedrine and 1-phenyl-2-propoanone (P-2-P) were already listed in Table I, and phenylacetic acid in Table II of the 1988 Convention when it came into force on 11 November 1990. 
Figure 10. Precursors for amphetamine and methamphetamine

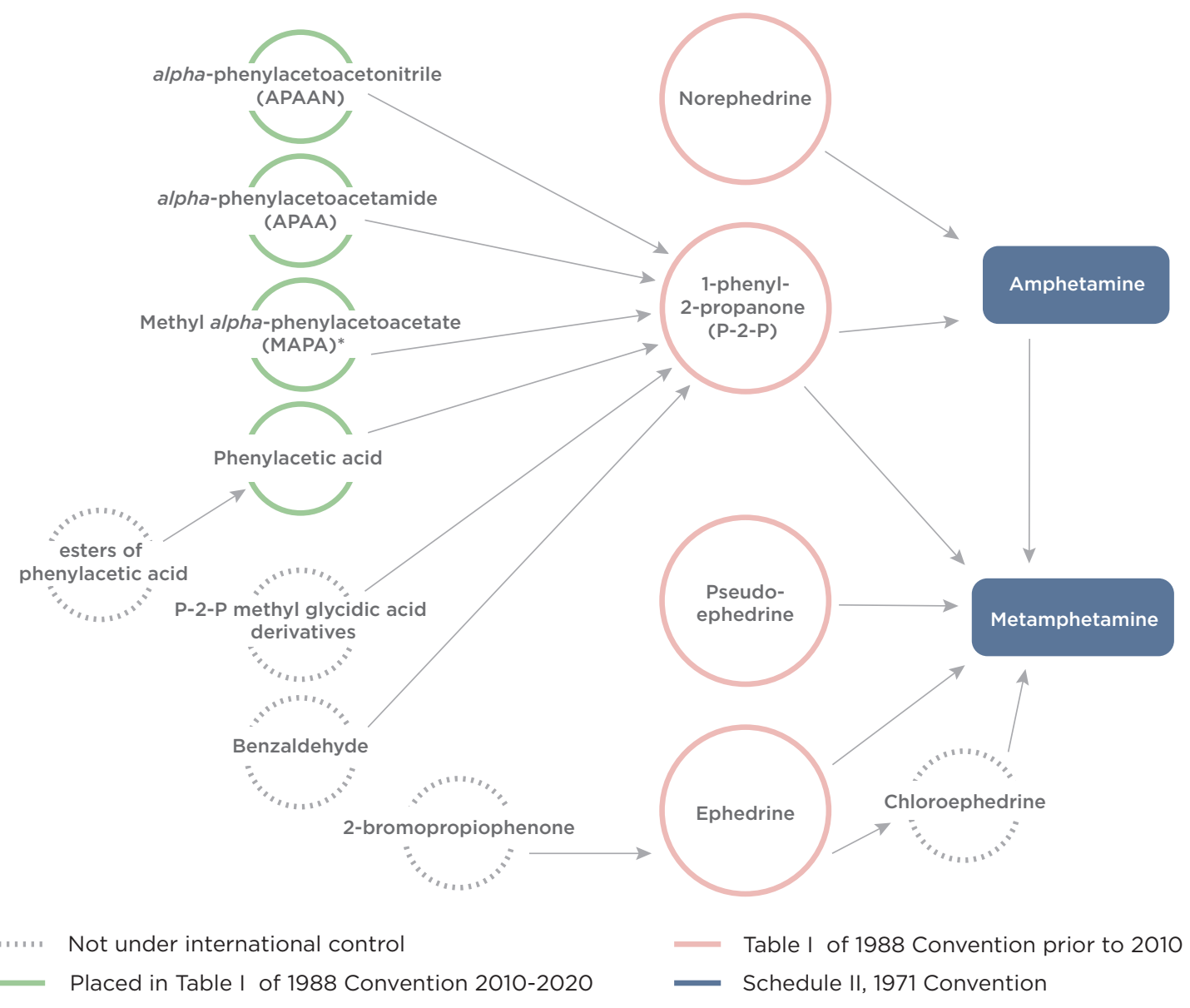

Source: UNODC elaboration.

*Placed in Table I, 1988 Convention at the sixty-third Commission on Narcotic Drugs, March 2020.

\section{Regional diversity in amphetamine and methamphetamine precursor developments}

Since the 1990s, illicit manufacturers in various parts of the world have complemented the use of traditional precursors with the use of non-controlled precursors and "designer" precursor chemicals to circumvent national or international controls and the efforts of law enforcement and industry to prevent the diversion of chemicals. ${ }^{32}$ Within this general trend, distinct national and regional variations can be observed due to factors such as differences in national precursor control regimes, illicit manufacturer capabilities and manufacturing costs. In East and South-East Asia, ephedrine and pseudoephedrine are the

\footnotetext{
${ }^{32}$ International Narcotics Control Board, various editions of the annual reports on Precursors and chemicals frequently used in the illicit manufacture of narcotic drugs and psychotropic substances.
}

predominant precursors used in the manufacture of methamphetamine, ${ }^{33}$ however, recent seizures of 2-bromopropiophenone ${ }^{34}$ (a non-controlled precursor for ephedrine), ${ }^{35}$ thionyl chloride ${ }^{36}$ (used for the manufacture of methamphetamine through the metal hydrogenation process using ephedrine and pseudoephedrine $)^{37,38}$ and P-2-P $\mathrm{P}^{39}$ indicate possible shifts in the types of precursor chemicals and synthetic routes

${ }^{33}$ UNODC, Synthetic Drugs in East and South-East Asia: Trends and Patterns of Amphetamine-type Stimulants and New Psychoactive Substances, 2019. ${ }^{34}$ Ibid.

${ }^{35}$ Ernest Fourneau, Process for the manufacture of phenyl-methyl-aminopropanol (synthetic ephedrine), Patent GB 302,940 (December 1928).

${ }^{36}$ UNODC, Transnational Organized Crime in Southeast Asia: Evolution, Growth and Impact, 2019.

${ }^{37}$ Hilde Emde, "Diastereoisomerism, III, Chloro and bromo ephedrine", Helvetica Chimica Acta, vol. 12, No. 1 (1929).

${ }^{38}$ Hilde Emde, "Diastereoisomerism, I, Configuration of ephedrine", Helvetica Chimica Acta, vol. 12, No. 1 (1929).

${ }^{39}$ UNODC, Transnational Organized Crime in Southeast Asia: Evolution, Growth and Impact, 2019. 
used. The change in synthetic routes and additional levels of processing required for some of these new emerging precursors also suggest increased sophistication among illicit manufacturing facilities in the region. In North America and Europe however, P-2-P synthetic routes dominate the illicit manufacture of amphetamine and methamphetamine. ${ }^{40}$ In North America, illicit manufacturers in Mexico have been observed in recent years to have switched back and forth between phenylacetic acid and its derivatives ("designer" precursors), ${ }^{41}$ benzaldehyde and nitroethane (general non-controlled precursors $)^{42,43}$ in the manufacture of $\mathrm{P}$-2-P, possibly in response to national controls on these substances. ${ }^{44,45,46,47}$

In Europe, the use of chemical intermediates in the manufacture of P-2-P, such as alpha-phenylacetoacetonitrile (APAAN), alpha-phenylacetoacetamide (APAA) and methyl alpha-phenylacetoacetate (MAPA), all of which were recently placed under international control, has intensified in recent years in order to circumvent controls on $\mathrm{P}-2-\mathrm{P}$, reduce manufacturing costs and ensure business continuity in illicit manufacturing. ${ }^{48,49}$ To a lesser extent, ephedrine and pseudoephedrine are the predominant precursors used in the domestic manufacture of

\footnotetext{
${ }^{40}$ International Narcotics Control Board, Precursors and chemicals frequently used in the illicit manufacture of narcotic drugs and psychotropic substances 2018 (United Nations publication, Sales No. E.19. XI.6).

${ }^{41}$ UNODC, Clandestine Manufacture of Substances under International Control (United Nations publication, ST/NAR/10/REV.3).

${ }^{42}$ Catherine B. Gairaud and Gerald R. Lappin, "The synthesis of w-nitrostyrenes.", Journal of Organic Chemistry, vol. 18, No. 1 (1953).

${ }^{43}$ Joseph B. Tindall, Process for preparing 1-aryl-2-oxoalkanes, Patent US 2,427,822 (September 1947).

${ }^{44}$ International Narcotics Control Board, Precursors and chemicals frequently used in the illicit manufacture of narcotic drugs and psychotropic substances 2018 (United Nations publication, Sales No. E.19. XI.6).

${ }^{45}$ International Narcotics Control Board, Precursors and chemicals frequently used in the illicit manufacture of narcotic drugs and psychotropic substances 2015 (United Nations publication, Sales No. E.16.XI.4).

${ }^{46}$ International Narcotics Control Board, Precursors and chemicals frequently used in the illicit manufacture of narcotic drugs and psychotropic substances 2012 (United Nations publication, Sales No. E.13.XI.4).

${ }^{47}$ United States, Department of Justice, Drug Enforcement Administration, 2018 National Drug Threat Assessment (Springfield, Strategic Intelligence Section, 2019).

${ }^{48}$ European Monitoring Centre for Drugs and Drug Addiction and Europol, EU Drug Markets Report 2019 (Luxembourg, Publications Office of the European Union, 2019).

${ }^{49}$ European Monitoring Centre for Drugs and Drug Addiction, Drug precursor developments in the European Union, EMCDDA Papers (Luxembourg, Publications Office of the European Union, 2019).
}

methamphetamine in Bulgaria, Czechia, Germany, Poland, Slovakia and the United States. ${ }^{50,51,52,53}$

\section{Precursor chemicals in the manufacture of "ecstasy"}

Safrole, isosafrole, piperonal and 3,4-methylenedioxyphenyl-2-propanone (3,4-MDP-2-P, PMK), which are all controlled under the 1988 Convention, are the most used precursor chemicals for the manufacture of "ecstasy". Of these, piperonal has the most widespread industrial use followed by safrole and isosafrole. Changes in the precursor chemicals used for the manufacture of "ecstasy" in recent years parallel those in the manufacture of amphetamine and methamphetamine, in that a number of non-controlled chemicals have been primarily used in the illicit manufacture of 3,4-MDP-2-P. Principal among these "designer" precursors are 3,4-MDP-2-P methyl glycidate and 3,4-MDP-2-P methyl glycidic acid, which have been increasingly found in seizures in Europe in recent years. Both precursors were placed in Table I of the 1988 Convention in 2019. Given the similarity between P-2-P and 3,4-MDP-2-P, it is possible that many of the "designer" precursors produced for the manufacture of methamphetamine could also be produced for the manufacture of "ecstasy". This is illustrated by the glycidate derivatives of 3,4-MDP-2-P mentioned above as well as a seizure of the "ecstasy" version of APAAN, namely 3,4-methylenedioxyphenylacetonitrile, in France in $2017 .{ }^{54}$ This is indicative of a crossover between the manufacture of different types of synthetic drugs and an example of the challenges faced by law enforcement and forensic personnel in investigating the clandestine manufacture of substances under international control.

\footnotetext{
${ }^{50}$ European Monitoring Centre for Drugs and Drug Addiction and Europol, EU Drug Markets Report 2019 (Luxembourg, Publications Office of the European Union, 2019).

${ }^{51}$ European Monitoring Centre for Drugs and Drug Addiction, Drug precursor developments in the European Union, EMCDDA Papers (Luxembourg, Publications Office of the European Union, 2019).

${ }^{52}$ International Narcotics Control Board, Precursors and chemicals frequently used in the illicit manufacture of narcotic drugs and psychotropic substances 2018 (United Nations publication, Sales No. E.19. XI.6).

${ }^{53}$ United States, Department of Justice, Drug Enforcement Administration, 2018 National Drug Threat Assessment (Springfield, Strategic Intelligence Section, 2019).

${ }^{54}$ European Monitoring Centre for Drugs and Drug Addiction, Drug precursor developments in the European Union, EMCDDA Papers (Luxembourg, Publications Office of the European Union, 2019).
} 
Figure 11. Precursors for "ecstasy"

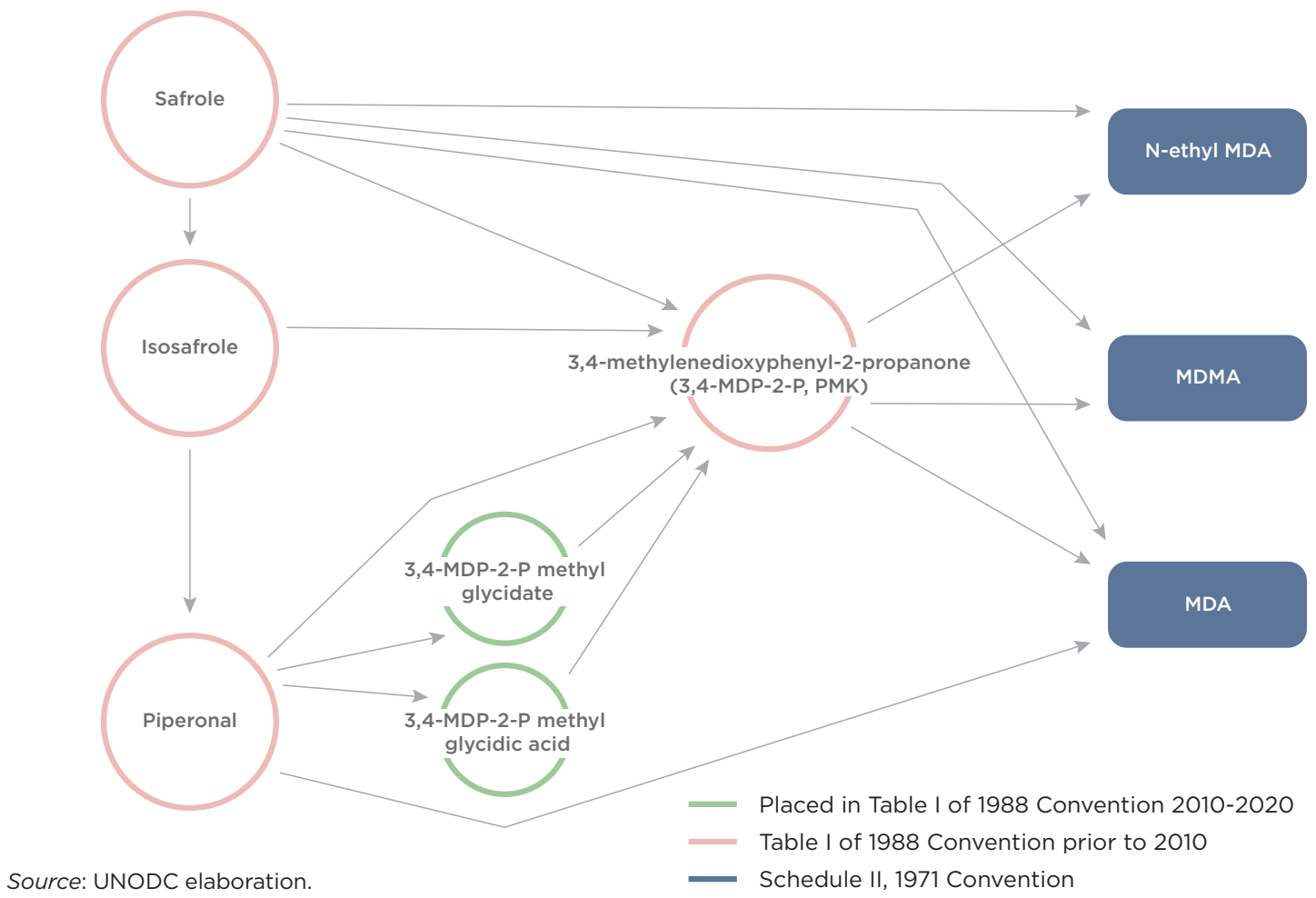

Precursor trends in the illicit manufacture of fentanyl and its analogues

In recent years there has been a significant increase in the number of fentanyl analogues appearing in synthetic drug markets. As a result, the primary precursor chemicals for the manufacture of fentanyl, $\mathrm{N}$-phenethyl-4-piperidone (NPP) and 4-anilino-N-phenethylpiperidine (ANPP), were placed in Table I of the 1988 Convention in 2017. In the interim period, there are indications that illicit fentanyl manufacturers have begun switching to alternative synthetic routes involving the use of non-controlled and/or "designer" precursor chemicals. ${ }^{55,56}$ (For more information please see the section on North America.)

${ }^{55}$ UNODC, Commission on Narcotic Drugs, "Decision 60/12 and 60/13: Inclusion of ANPP and NPP in Table I of the United Nations Convention against Illicit Traffic in Narcotic Drugs and Psychotropic Substances of 1988., Report on the sixtieth session (2 December 2016 and 13-17 March 2017), ECOSOC, Official Records, 2017, Supplement No. 8, p. 39.

${ }^{56}$ For further technical information on non-scheduled and "designer" precursors, please refer to UNODC, "An expanding synthetic drugs market - Implications for precursor control”, Global SMART Update, vol. 23 (March 2020).

Figure 12. Precursors for fentanyl

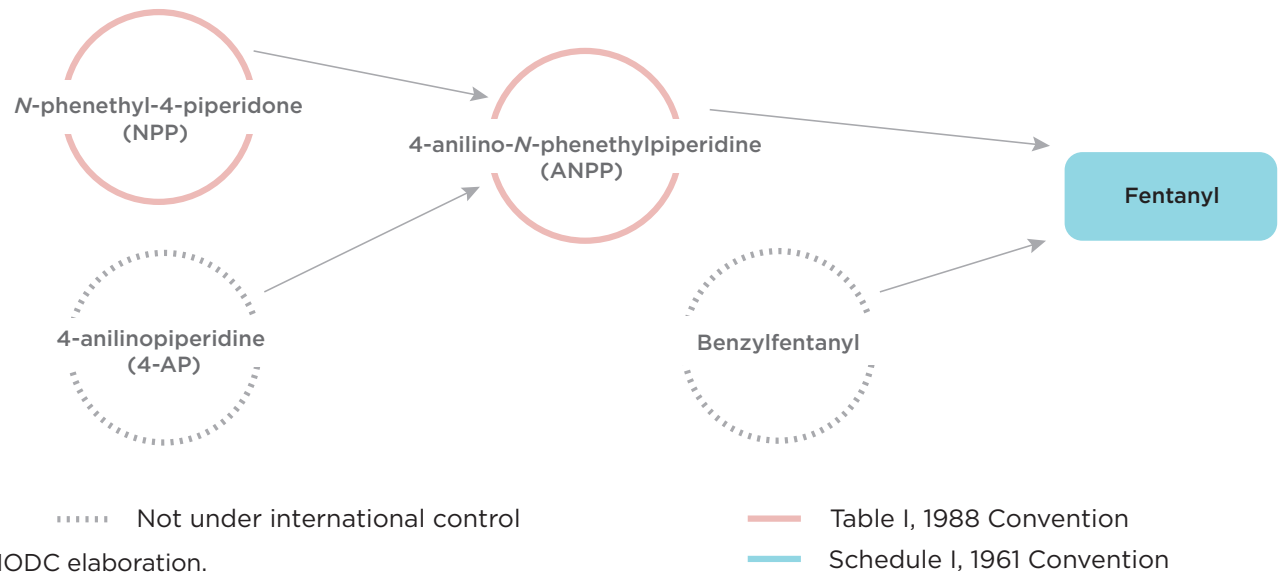




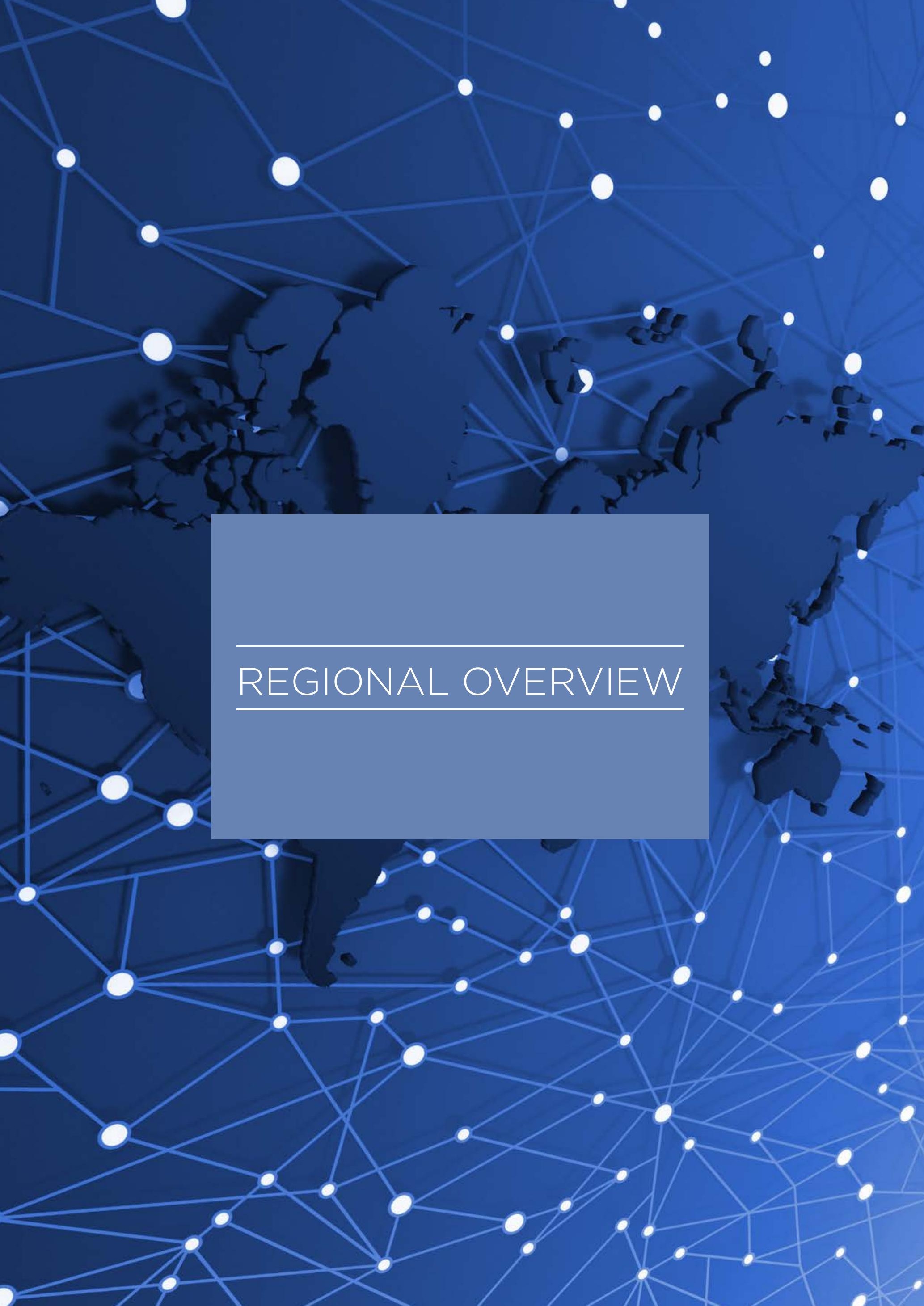


REGIONAL OVERVIEW

AFRICA 


\section{Key findings}

\section{Tramadol}

- Almost half of all countries in Africa have reported non-medical use, seizures or trafficking of tramadol between 2015 to 2019 with most of them located in West, Central and North Africa.

- The non-medical use of tramadol has become a growing concern particularly among men, young people and manual or construction workers.

- Tramadol is trafficked mainly from Asia to countries in West, Central and North Africa.

- Large quantities of tramadol were seized in the period 2014-2019 with annual amounts fluctuating between 13 tons and 112 tons. The peaks in seizures, in several years, reflect huge individual shipments seized by some countries.

\section{Methamphetamine}

- The quantities of methamphetamine seized and the number of countries reporting seizures have increased over the past years mostly in West and Southern Africa.

- Methamphetamine manufacture in West and Southern Africa has expanded with 13 clandestine laboratories reported in 2018.

- Ephedrine and pseudoephedrine remain the primary precursors used in the illicit manufacture of methamphetamine.

- Methamphetamine from the region is mainly trafficked to East and South-East Asia, Oceania, and Western and Central Europe but some proportion remains in the region for domestic use.

- Use of methamphetamine is present among vulnerable populations and is associated with increased risk and harm.

\section{"Ecstasy"}

- For the first time in 2018, "ecstasy" manufacture has been reported from South Africa with two laboratories dismantled.

- There are indications of a growing "ecstasy" market in North and Southern Africa with annual increases in the quantities of "ecstasy" seized over the period 2014-2018.

- Increasing use of "ecstasy" has been reported among young people. 
REGIONAL OVERVIEW

AMERICAS 


\section{Key findings}

\section{"Ecstasy"}

- The quantities of "ecstasy" seized in the region remained stable with the highest seizures made in South America and small increases reported in Central America and some Caribbean countries.

- While "ecstasy" is mostly trafficked into the region from Western and Southern Europe, countries in the Caribbean and South America have reported "ecstasy" manufacture.

- The "ecstasy" market has become more complex as tablets containing high doses of MDMA have emerged.

- MDMA is also available in powder and crystalline form, and "ecstasy" products may contain substances other than MDMA, including NPS with stimulant effects.

\section{New psychoactive substances}

- In Central America, South America and the Caribbean, 210 NPS from 15 countries had been reported up to August 2020, mostly stimulants and classic hallucinogens.

- In Central and South America, NBOMe compounds continue to be sold as LSD, reflected in forensic analysis of LSD samples.

- Samples sold as 2C-B or "cocaina rosada" in Central America and South America often contain other substances, for instance, ketamine, amphetamine, MDMA or a range of NPS.

\section{Tranquilizers}

- The non-medical use of tranquilizers such as benzodiazepines and barbiturates has been increasing in Central and South American countries particularly among females, secondary school students and university students. 


\section{Key findings}

\section{Methamphetamine}

- The quantities of methamphetamine seized in North America have continuously increased from about 58 tons in 2014 to almost 117 tons in 2018.

- Extensive methamphetamine manufacture has been reported in Mexico and the United States.

- Methamphetamine from Mexico is increasingly being trafficked to the United States and to other parts of the world such as Europe, East and South-East Asia and Oceania as indicated by seizures made in Mexico and destination countries.

- Increasing availability of low-cost and high-purity methamphetamine is reported, as the number of drug poisoning deaths involving psychostimulants, mostly methamphetamine, has surged.

- Methamphetamine use in the general population increased in the United States and Canada.

- The risk of methamphetamine use is increasing due to the drug being sold as "ecstasy" and falsified Adderall ${ }^{\circledast}$ and Xanax ${ }^{\circledast}$ tablets.

\section{Fentanyl and fentanyl analogues}

- Deaths involving synthetic opioids, especially fentanyl and its analogues, continue to remain a significant concern in North America.

- The quantities of fentanyl seized in North America have grown sixfold from about 0.4 tons in 2016 to 2.9 tons in 2018.

\section{Precursors}

- Alternate synthetic routes and non-scheduled precursor chemicals used in the illicit manufacture of fentanyl have emerged in response to NPP and ANPP being placed under international control in 2017. 
REGIONAL OVERVIEW

ASIA AND OCEANIA 

TRANSCAUCASIA
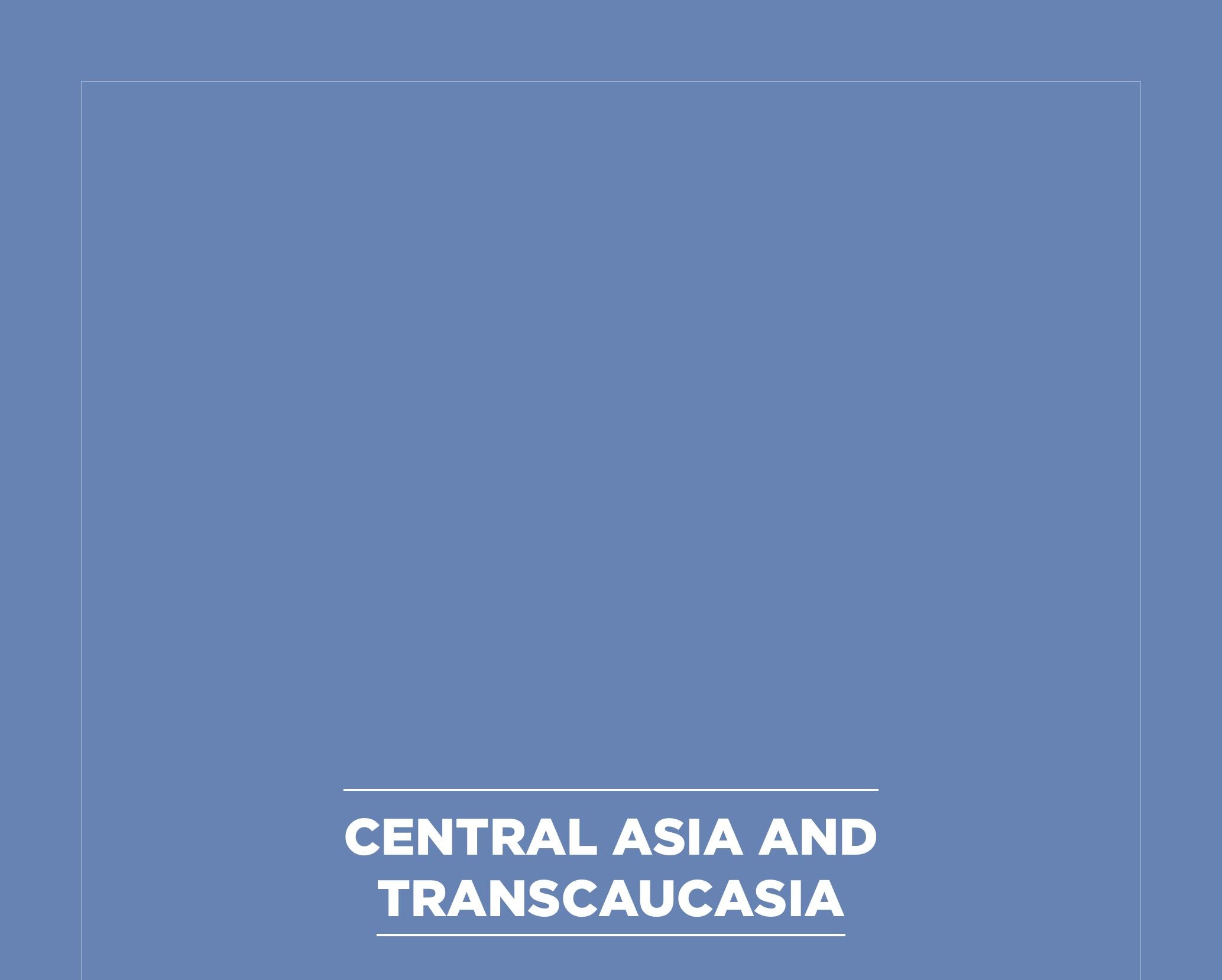


\section{Key findings}

\section{Methamphetamine}

- The quantities of methamphetamine seized rapidly increased in the region during the past five years.

- Methamphetamine seized in the region reportedly originated from Iran (Islamic Republic of) and more recently from Afghanistan.

- Central Asia and Transcaucasia appears to be a transit point for methamphetamine trafficking to Africa, East Asia, North America and Oceania.

\section{"Ecstasy"}

- A geographic expansion of "ecstasy" was noted, with 7 out of 8 countries in the region reporting seizures in 2018.

- A high number of reports indicate that "ecstasy" is trafficked from European countries including the Netherlands and Turkey to Central Asia and Transcaucasia.

\section{New psychoactive substances}

- Several countries in Central Asia and Transcaucasia reported the emergence of NPS, with 119 substances identified until August 2020.

- After decreases in the number of NPS on the market in 2017 and 2018, the number of substances increased by 65 per cent in 2019.

- The recent emergence of clandestine manufacturing of stimulants and synthetic cannabinoid receptor agonists might indicate an expanding NPS market in the region.

\section{Synthetic opioids}

- The appearance of synthetic opioids in Central Asia and Transcaucasia in recent years may suggest that the region is not immune to the opioid crisis, which mainly affects North America and parts of Africa. 
EAST AND SOUTH-EAST ASIA AND OCEANIA 


\section{Key findings}

\section{Methamphetamine}

- Synthetic drugs, in particular methamphetamine, dominate the illicit drug market in East and South-East Asia, the region with the fastest growing methamphetamine market in the world.

- Manufacture of methamphetamine around the Golden Triangle as well as in Cambodia and Viet Nam shows signs of expansion, while other countries in East and South-East Asia experience a corresponding decline in the number of clandestine laboratories seized. This phenomenon strongly indicates a consolidation of methamphetamine production in the Greater Mekong Subregion.

- Despite record-setting seizures, the purity of methamphetamine is increasing while retail prices are decreasing in East and South-East Asia.

- Significant quantities of crystalline methamphetamine and precursor chemicals continue to be trafficked from East and South-East Asia to Oceania.

- Intensified effort in the trafficking of methamphetamine and associated precursor chemicals by transnational organized crime groups operating in East and South-East Asia region is a major driving force behind the increase in the region's methamphetamine production and supply in recent years.

\section{"Ecstasy"}

- The use of "ecstasy" is not perceived as widespread. However, there is a growing availability of "ecstasy" in crystalline form as well as tablets containing high doses of MDMA trafficked from Europe.

- MDMA manufacture may be spreading from the maritime South-East Asian countries to some countries in the Greater Mekong Subregion.

- Tablet preparations sold as "ecstasy" but containing substances other than MDMA, including new psychoactive substances (NPS), continue to be found in the region.

\section{New psychoactive substances}

- A total of 511 individual NPS were reported from countries in East and South-East Asia and Oceania to the UNODC Early Warning Advisory until August 2020.

- Potent synthetic opioids including fentanyl and NPS with opioid effects are being identified and increasing annually in some countries in the East and South-East Asia and Oceania.

- Clandestine ketamine laboratories dismantled in a larger number of countries in South-East Asia, accompanied by substantial increases in seizures, point to a geographic shift of manufacture.

\section{GHB and GBL}

- Seizures and increasing use of GHB and GBL are reported by some countries in East and SouthEast Asia and Oceania. 
THE NEAR AND MIDDLE EAST 


\section{Key findings}

\section{Amphetamine}

- The largest quantities of amphetamine seized worldwide continue to be reported from Saudi Arabia, Jordan, United Arab Emirates and Lebanon (in order of aggregated amount seized).

- Most amphetamine seized in the region is reported to have originated in Lebanon and the Syrian Arab Republic, with manufacture reported from Jordan.

- Europe plays an increasingly important role in "captagon" trafficking to and from countries in the Near and Middle East.

\section{Methamphetamine}

- Increases in quantities of crystalline methamphetamine seized in recent years suggest that the methamphetamine market in the region is expanding.

- Methamphetamine is trafficked from countries in East and South-East Asia, South Asia, and Western and Central Europe, to the Near and Middle East.

\section{Tramadol}

- Non-medical use of tramadol continues to expand in countries in the Near and Middle East.

- Tramadol seems to be mostly trafficked to the region for domestic use from North Africa, West and Central Africa, and South Asia.

\section{New psychoactive substances}

- New psychoactive substances, mainly synthetic cannabinoid receptor agonists, continue to be reported from the region. 
SOUTH ASIA

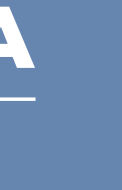

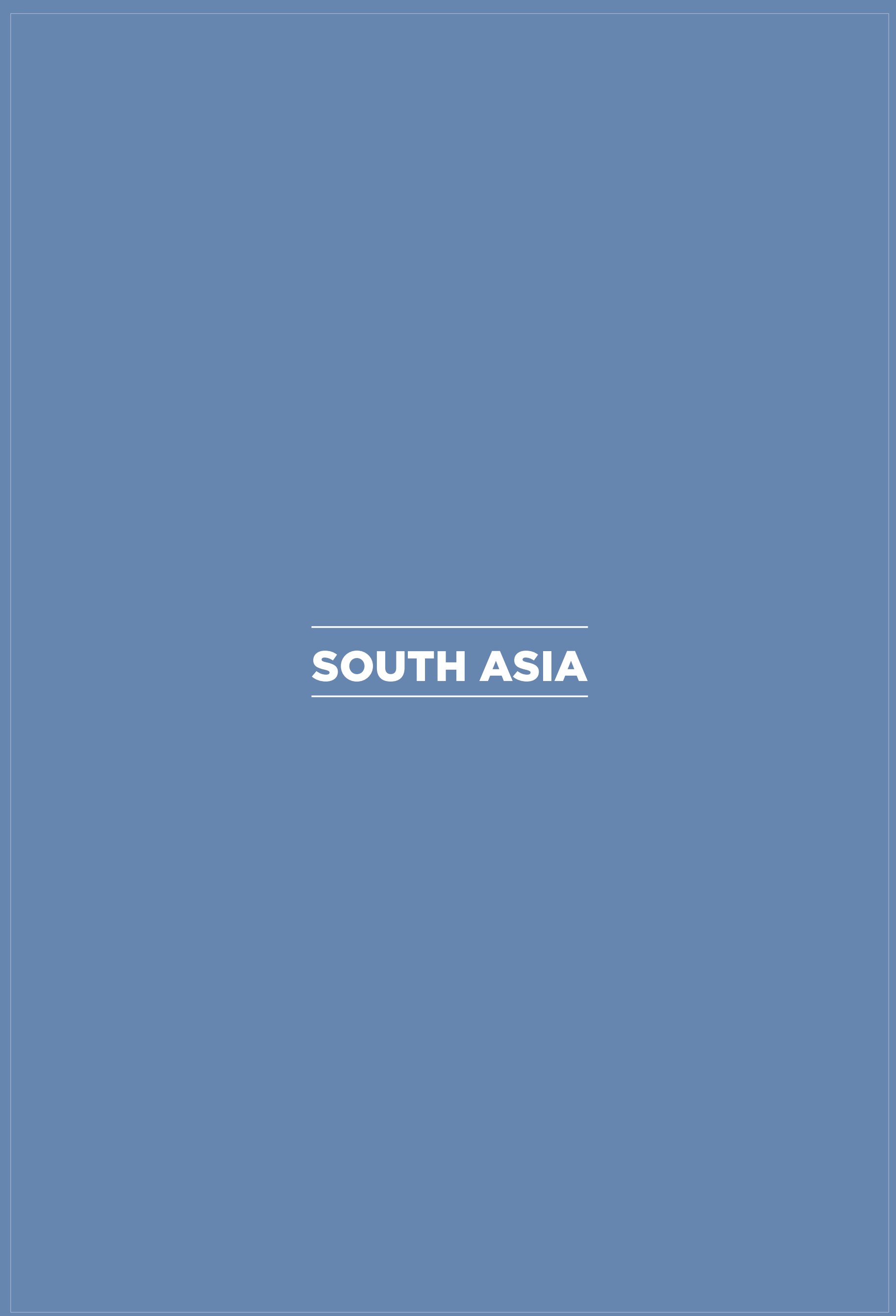




\section{Key findings}

\section{Amphetamine-type stimulants}

- The ATS market in South Asia has expanded in recent years, with upward trends in the overall quantities of amphetamine, methamphetamine and ecstasy-type substances seized annually.

- The supply-led expansion of ATS trafficking has seemingly led to growing ATS use in the region.

\section{Methamphetamine}

- The marked increase in methamphetamine seizures in the region is likely to be a result of growing transport connectivity within Asia, and intensification of methamphetamine manufacture and trafficking from neighbouring East, South-East and South-West Asia.

\section{Precursors}

- India's booming pharmaceutical and precursor exports, combined with its scientific expertise and manufacturing capabilities, may present significant challenges for authorities in exercising controls over the diversion, clandestine manufacture and trafficking of precursor chemicals.

- Trafficking of ATS precursors from India remains significant, with key trafficking destinations including countries in Africa, East and South-East Asia, Oceania and the Near and Middle East.

- Seizures of other synthetic drug precursors including $N$-acetylanthranilic acid, $N$-phenethyl-4piperidone (NPP) and 2-bromo-4-chloropropiophenone trafficked from or within India were also reported. 
$\underline{\text { SOUTH-WEST ASIA }}$

$$
\text { A }
$$
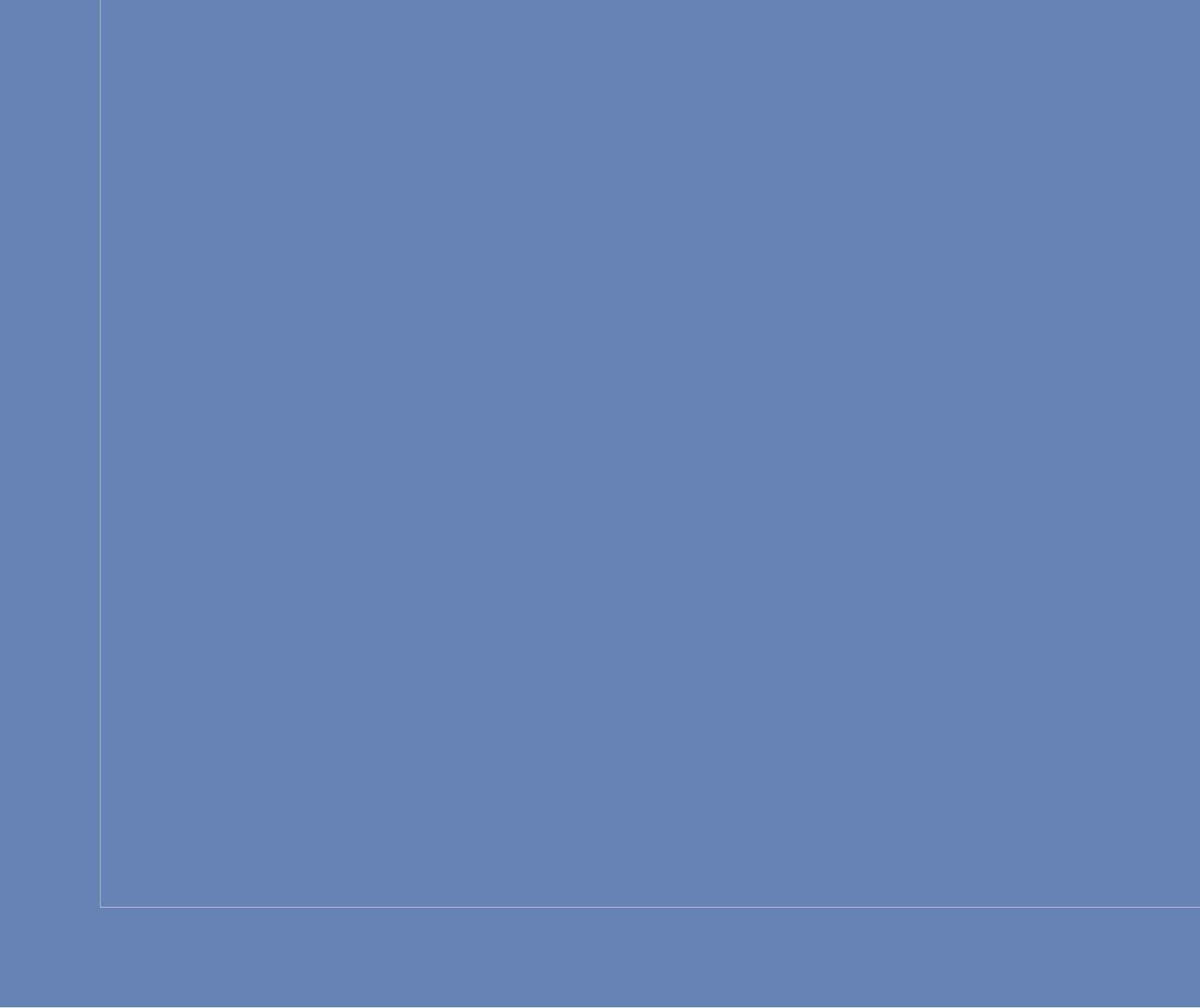


\section{Key findings}

\section{Methamphetamine}

- The market for methamphetamine has seen a large increase across all countries in the region.

- Seizure quantities tripled from 1.9 tons in 2016 to 6.1 tons in 2018 and further increased in 2019.

- Key opiate trafficking routes in the region are being used to traffic methamphetamine towards other regions such as Asia, Europe, the Near and Middle East and Oceania.

- There appears to be a growing number of methamphetamine manufacturing facilities operating within Afghanistan, especially in the provinces bordering the Islamic Republic of Iran.

- There are indications of increasing concomitant use of methamphetamine and opioids in the region while the perceived risks regarding the harm and dependence potential of methamphetamine remain low among users.

\section{Amphetamine}

- Amphetamine remains a key fixture in Pakistan, with early indications of an expansion into Afghanistan. 
REGIONAL OVERVIEW EUROPE 


\section{Key findings}

\section{Amphetamine}

- Europe plays an increasingly important role in the global market for amphetamine with manufacture remaining concentrated in the region, and subsequent trafficking to the Americas, Central Asia and Transcaucasia, East and South-East Asia, the Near and Middle East, North Africa and Oceania.

- Europe is possibly the origin of increasing amounts of "captagon" tablets destined for the Middle East and serves as a transit region for "captagon" trafficking from the Syrian Arab Republic to the Arabian Peninsula.

- Amphetamine continues to be more commonly used than methamphetamine in most European countries.

\section{Methamphetamine}

- The availability of methamphetamine in Europe and its use has been slowly increasing and spreading geographically.

- Methamphetamine manufacture has extended beyond Central Europe to Belgium and the Netherlands, with increasing evidence of the involvement of transnational organized crime groups.

- The methamphetamine manufactured in Africa and Mexico transits through Europe, usually destined for in East and South-East Asia and Oceania.

\section{"Ecstasy"}

- The quantities of "ecstasy" seized have almost doubled over the past five years, and the number of seizure cases is increasing.

- The MDMA content of "ecstasy" tablets has risen significantly increasing the risk associated with its use.

- "Ecstasy" tablets are manufactured in Europe and trafficked to consumer markets globally.

\section{New psychoactive substances}

- In Europe, 875 different NPS from 42 European countries had been reported by August 2020, mostly stimulants, synthetic cannabinoid receptor agonists and classic hallucinogens.

- Interactions between the NPS market and traditional drugs have become stronger, with NPS sold alongside or in a mixture with other drugs.

- Synthetic cannabinoids and synthetic cathinones continue to be used by high-risk and marginalized groups such as people who inject drugs, the homeless and prison populations.

- A larger number of synthetic opioids such as fentanyl analogues and benzodiazepine-type NPS have appeared on the NPS market and are associated with emergency-room and death cases.

\section{Precursors}

- The continuous innovation of pre-precursor chemicals used in the manufacture of synthetic drugs prevails, as demonstrated by large shifts in the types and quantities of pre-precursors seized annually. 


\section{UNODC publications}

Afghanistan Synthetic Drug Situation Assessment, UNODC Global SMART Programme (January 2017).

Central Asia Synthetic Drugs Situation Assessment - A Report from the UNODC Global SMART Programme (December 2017).

Clandestine Manufacture of Substances under International Control (March 2013).

Current NPS Threats, vol. II (January 2020).

Early Warning Advisory Newsclip: Chile: Police dismantle clandestine laboratory suspected of manufacturing 25I-NBOMe (July 2017).

Early Warning Advisory Newsclip: Trinidad and Tobago: Minister of National Security alerts public on health risks of synthetic drugs (April 2019).

Global SMART Newsletter for Latin America and the Caribbean, No. 3 (March 2019). Available at https:// mailchi.mp/57b4e9fc292f/c8h95kwi0q-257735

Global SMART Newsletter for Latin America and the Caribbean, No. 5 (October 2019). Available at mailchi. $\mathrm{mp} / \mathrm{c} 70560380 \mathrm{~b} 45 /$ lacnewslettervol5-372887

Global SMART Newsletter for Latin America and the Caribbean, No. 6 (June 2020). Available at us 19.campaignarchive.com/? $\mathrm{u}=\mathrm{bbcbd} 512 \mathrm{dfc} 446 \mathrm{a} 42 \mathrm{c} 12351 \mathrm{~d} 3 \& \mathrm{id}$ $=43 \mathrm{ea} 75 \mathrm{f} 0 \mathrm{bc}$

Global SMART Update: The non-medical use of benzodiazepines: A growing threat to public health? vol. 18 (September 2017).

Global SMART Update: Methamphetamine continues to dominate synthetic drug markets, vol. 20 (August 2018).

Global SMART Update: Understanding the global opioid crisis, vol. 21 (March 2019).

Global SMART Update: The ATS market - 10 years after the 2009 Plan of Action, vol. 22 (September 2019).

Global SMART Update: An expanding synthetic drugs market - Implications for precursor control, vol. 23 (March 2020).
Global SMART Update: The growing complexity of the opioid crisis, vol. 24 (October 2020).

Guidelines for the Safe Disposal of Chemicals used in the Illicit Manufacture of Drugs (September 2011).

Illustrated Guide for the Disposal of Chemicals used in the Illicit Manufacture of Drugs (October 2017).

Research Brief: COVID-19 and the drug supply chain: from production and trafficking to use (May 2020).

Synthetic Drugs in East and South-East Asia: Trends and Patterns of Amphetamine-type Stimulants and New Psychoactive Substances (March 2019).

Synthetic Drugs in East and South-East Asia: Latest Developments and Challenges (May 2020).

Terminology and Information on Drugs (March 2016).

Transnational Organized Crime in South-East Asia: Evolution, Growth and Impact (July 2019).

Voices of the Quchaqbar - Understanding opiate trafficking in Afghanistan from the perspective of drug traffickers, AOTP Update Special Edition (January 2020).

World Drug Report 2017 (June 2017).

World Drug Report 2018 (June 2018).

World Drug Report 2019 (June 2019).

World Drug Report 2020 (June 2020).

\section{Joint UNODC publications}

Drug use survey conducted in 2016 among university students in Bolivia, Colombia, Ecuador and Peru - II Estudio epidemiológico andino sobre consumo de drogas en la población universitaria, Informe Regional 2016 (June 2017).

Drug Use Survey in Nigeria 2018 (Vienna, 2019).

Illicit Drug Use in Palestine (November 2017). 


\section{Glossary}

Amphetamine-type stimulants: a group of substances composed of synthetic stimulants controlled under the Convention on Psychotropic Substances of 1971 and from the group of substances called amphetamines, which includes amphetamine, methamphetamine, methcathinone and the "ecstasy"-group substances (3,4-methylenedioxymethamphetamine (MDMA) and its analogues).

Amphetamines: a group of amphetamine-type stimulants that includes amphetamine and methamphetamine.

Annual or past-year prevalence: the total number of people of a given age range who have used a given drug at least once in the past year, divided by the number of people of the given age range, and expressed as a percentage.

Dependence: defined in the International Statistical Classification of Diseases and Related Health Problems (tenth revision) as a cluster of physiological, behavioural and cognitive phenomena that develop after repeated substance use and that typically include a strong desire to take the drug, difficulties in controlling its use, persisting in its use despite harmful consequences, a higher priority given to drug use than to other activities and obligations, increased tolerance, and sometimes a physical withdrawal state.

Drug use: use of controlled psychoactive substances for non-medical and non-scientific purposes, unless otherwise specified.

Harmful use of substances: defined in the International Statistical Classification of Diseases and Related Health Problems (tenth revision) as a pattern of use that causes damage to physical or mental health.

New psychoactive substances: substances of abuse, either in a pure form or a preparation, that are not controlled under the Single Convention on Narcotic Drugs of 1961 or the 1971 Convention, but that may pose a public health threat. In this context, the term "new" does not necessarily refer to new inventions but to substances that have recently become available. For the purpose of the report, NPS that have been placed under international control since 2014 continue to be included under the term NPS to enable times series analysis.
Opiates: a subset of opioids comprising the various products derived from the opium poppy plant, including opium, morphine and heroin.

Opioids: a generic term that refers both to opiates and their synthetic analogues (mainly prescription or pharmaceutical opioids) and compounds synthesized in the body.

People who suffer from drug use disorders/ people with drug use disorders: a subset of people who use drugs. Harmful use of substances and dependence are features of drug use disorders. People with drug use disorders need treatment, health and social care, and rehabilitation.

Prevention of drug use and treatment of drug use disorders: the aim of "prevention of drug use" is to prevent or delay the initiation of drug use, as well as the transition to drug use disorders. Once a person develops a drug use disorder, treatment, care and rehabilitation are needed.

Problem drug users: people who engage in the high-risk consumption of drugs. For example, people who inject drugs, people who use drugs on a daily basis and/or people diagnosed with drug use disorders (harmful use or drug dependence), based on clinical criteria described in the Diagnostic and Statistical Manual of Mental Disorders (fifth edition) of the American Psychiatric Association, or the International Classification of Diseases and Related Health Problems (tenth revision) of WHO.

Substance or drug use disorders: referred to in the Diagnostic and Statistical Manual of Mental Disorders (fifth edition) as patterns of symptoms resulting from the repeated use of a substance despite experiencing problems or impairment in daily life as a result of using substances. Depending on the number of symptoms identified, substance use disorder may be mild, moderate or severe.

Synthetic drugs: includes any substance of synthetic origin with psychoactive effects available on the illicit drug market and/or used for non-medical purposes.

Synthetic opioids: fentanyl, fentanyl analogues and new synthetic opioids. 


\section{Regional groupings}

The Global Synthetic Drugs Assessment 2020 uses a number of regional and subregional designations. These are not official designations, and are defined as follows:

\section{Africa}

- East Africa: Burundi, Comoros, Djibouti, Eritrea, Ethiopia, Kenya, Madagascar, Mauritius, Rwanda, Seychelles, Somalia, South Sudan, Uganda, United Republic of Tanzania and Mayotte

- North Africa: Algeria, Egypt, Libya, Morocco, Sudan and Tunisia

- Southern Africa: Angola, Botswana, Eswatini, Lesotho, Malawi, Mozambique, Namibia, South Africa, Zambia, Zimbabwe and Reunion

- West and Central Africa: Benin, Burkina Faso, Cabo Verde, Cameroon, Central African Republic, Chad, Congo, Côte d'Ivoire, Democratic Republic of the Congo, Equatorial Guinea, Gabon, Gambia, Ghana, Guinea, Guinea-Bissau, Liberia, Mali, Mauritania, Niger, Nigeria, Sao Tome and Principe, Senegal, Sierra Leone, Togo and Saint Helena

\section{Americas}

- Caribbean: Antigua and Barbuda, Bahamas, Barbados, Cuba, Dominica, Dominican Republic, Grenada, Haiti, Jamaica, Saint Kitts and Nevis, Saint Lucia, Saint Vincent and the Grenadines, Trinidad and Tobago, Anguilla, Aruba, Bonaire, Netherlands, British Virgin Islands, Cayman Islands, Curaçao, Guadeloupe, Martinique, Montserrat, Puerto Rico, Saba, Netherlands, Sint Eustatius, Netherlands, Sint Maarten, Turks and Caicos Islands and United States Virgin Islands

- Central America: Belize, Costa Rica, El Salvador, Guatemala, Honduras, Nicaragua and Panama

- North America: Canada, Mexico and United States of America, Bermuda, Greenland and Saint-Pierre and Miquelon

- South America: Argentina, Bolivia (Plurinational State of), Brazil, Chile, Colombia, Ecuador, Guyana, Paraguay, Peru, Suriname, Uruguay, Venezuela (Bolivarian Republic of) and Falkland Islands (Malvinas)
Asia

- Central Asia and Transcaucasia: Armenia, Azerbaijan, Georgia, Kazakhstan, Kyrgyzstan, Tajikistan, Turkmenistan and Uzbekistan

- East and South-East Asia: Brunei Darussalam, Cambodia, China, Democratic People's Republic of Korea, Indonesia, Japan, Lao People's Democratic Republic, Malaysia, Mongolia, Myanmar, Philippines, Republic of Korea, Singapore, Thailand, Timor-Leste, Viet Nam, Hong Kong, China, Macao, China, and Taiwan Province of China

- Greater Mekong Subregion: Cambodia, China, Lao People's Democratic Republic, Myanmar, Thailand and Viet Nam

- South-West Asia: Afghanistan, Iran (Islamic Republic of) and Pakistan

- Near and Middle East: Bahrain, Iraq, Israel, Jordan, Kuwait, Lebanon, Oman, Qatar, Saudi Arabia, State of Palestine, Syrian Arab Republic, United Arab Emirates and Yemen

- South Asia: Bangladesh, Bhutan, India, Maldives, Nepal and Sri Lanka

\section{Europe}

- Eastern Europe: Belarus, Republic of Moldova, Russian Federation and Ukraine

- South-Eastern Europe: Albania, Bosnia and Herzegovina, Bulgaria, Croatia, Montenegro, North Macedonia, Romania, Serbia, Turkey and Kosovo*

- Western and Central Europe: Andorra, Austria, Belgium, Cyprus, Czechia, Denmark, Estonia, Finland, France, Germany, Greece, Hungary, Iceland, Ireland, Italy, Latvia, Liechtenstein, Lithuania, Luxembourg, Malta, Monaco, Netherlands, Norway, Poland, Portugal, San Marino, Slovakia, Slovenia, Spain, Sweden, Switzerland, United Kingdom of Great Britain and Northern Ireland, Faroe Islands, Gibraltar and Holy See

"All references to Kosovo in this report should be understood to be in compliance with Security Council resolution 1244 (1999). 


\section{Oceania}

- Australia and New Zealand: Australia and New Zealand

- Polynesia: Cook Islands, Niue, Samoa, Tonga, Tuvalu, French Polynesia, Tokelau and Wallis and Futuna Islands
- Melanesia: Fiji, Papua New Guinea, Solomon Islands, Vanuatu and New Caledonia

- Micronesia: Kiribati, Marshall Islands, Micronesia (Federated States of), Nauru, Palau, Guam and Northern Mariana Islands 

UNODC 